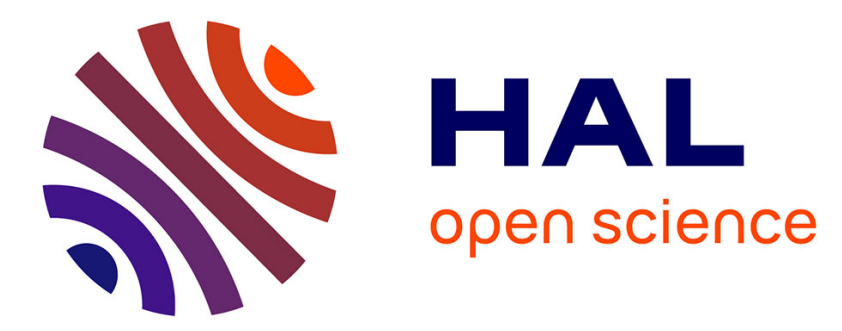

\title{
Tetrahedral and Cuboidal Clusters in Complexes of Uranyl and Alkali or Alkaline-Earth Metal Ions with rac- and (1R,2R)-trans-1,2-Cyclohexanedicarboxylate
} Pierre Thuéry, Jack Harrowfield

\section{- To cite this version:}

Pierre Thuéry, Jack Harrowfield. Tetrahedral and Cuboidal Clusters in Complexes of Uranyl and Alkali or Alkaline-Earth Metal Ions with rac- and (1R,2R)-trans-1,2-Cyclohexanedicarboxylate. Crystal Growth \& Design, 2017, 17, pp.2881-2892. 10.1021/acs.cgd.7b00448 . cea-01510312

\author{
HAL Id: cea-01510312 \\ https://hal-cea.archives-ouvertes.fr/cea-01510312
}

Submitted on 19 Apr 2017

HAL is a multi-disciplinary open access archive for the deposit and dissemination of scientific research documents, whether they are published or not. The documents may come from teaching and research institutions in France or abroad, or from public or private research centers.
L'archive ouverte pluridisciplinaire HAL, est destinée au dépôt et à la diffusion de documents scientifiques de niveau recherche, publiés ou non, émanant des établissements d'enseignement et de recherche français ou étrangers, des laboratoires publics ou privés.

\section{(c)(1)}

Distributed under a Creative Commons Attribution| 4.0 International License 


\title{
Tetrahedral and Cuboidal Clusters in Complexes of Uranyl and Alkali or Alkaline-Earth Metal Ions with rac- and $(1 R, 2 R)$-trans-1,2-Cyclohexanedicarboxylate
}

\author{
Pierre Thuéry*,† and Jack Harrowfield ${ }^{*,+}$ \\ ${ }^{\dagger}$ NIMBE, CEA, CNRS, Université Paris-Saclay, CEA Saclay, 91191 Gif-sur-Yvette, France \\ †ISIS, Université de Strasbourg, 8 allée Gaspard Monge, 67083 Strasbourg, France
}

\begin{abstract}
Uranyl nitrate was treated with racemic or enantiopure $(1 R, 2 R)$ forms of trans-1,2cyclohexanedicarboxylic acid ( $\mathrm{H}_{2}$ chdc and $R-\mathrm{H}_{2}$ chdc, respectively) in the presence of additional cations, mostly alkali or alkaline-earth metal cations, under solvo-hydrothermal conditions to generate a series of one homo- and seven heterometallic complexes which all contain the pseudotetrahedral $\left[\left(\mathrm{UO}_{2}\right)_{4}((R-) \text { chdc })_{6}\right]^{4-}$ cluster previously found in sodium(I)-, silver(I)- and lead(II)-containing derivatives. These clusters are for the first time obtained as isolated species in $\left[\mathrm{NH}_{4}\right]_{4}\left[\left(\mathrm{UO}_{2}\right)_{4}(\mathrm{chdc})_{6}\right](\mathbf{1})$, in which the ammonium cations are held by hydrogen bonds close to the faces of the tetrahedron. In both compounds $\left[\left(\mathrm{UO}_{2}\right)_{4} \mathrm{~K}_{4}(R \text {-chdc })_{6}\left(\mathrm{H}_{2} \mathrm{O}\right)_{6}\right](2)$ and $\left[\left(\mathrm{UO}_{2}\right)_{4} \mathrm{Ba}_{2}(R \text {-chdc })_{6}\left(\mathrm{H}_{2} \mathrm{O}\right)_{8}\right](\mathbf{8})$, the uranyl tetrahedra are assembled into three-dimensional frameworks by bridging potassium(I) or barium(II) cations, these being bound to carboxylate groups from different clusters. A closer association of uranyl tetrahedra and countercations is found with alkali metal ions of larger ionic radius, leading to the formation of heterometallic cuboidal clusters. The three rubidium(I)-containing compounds $\quad\left[\mathrm{H}_{2} \mathrm{NMe}_{2}\right]\left[\left(\mathrm{UO}_{2}\right)_{4} \mathrm{Rb}_{3}(R \text {-chdc })_{6}\left(\mathrm{H}_{2} \mathrm{O}\right)_{1.75}\right] \quad(\mathbf{3}), \quad\left[\left(\mathrm{UO}_{2}\right)_{4} \mathrm{Rb}_{4}(R\right.$ chdc $\left.)_{6}(\mathrm{NMP})_{0.5}\left(\mathrm{H}_{2} \mathrm{O}\right)_{3.75}\right] \cdot 0.5 \mathrm{NMP} \cdot 0.25 \mathrm{H}_{2} \mathrm{O}$ (4), and $\left[\left(\mathrm{UO}_{2}\right)_{4} \mathrm{Rb}_{4}(R \text {-chdc })_{6}\left(\mathrm{H}_{2} \mathrm{O}\right)_{1.5}\right] \cdot 0.5 \mathrm{H}_{2} \mathrm{O}$ (5) form a regular progression, the incomplete heptanuclear cuboids found in $\mathbf{3}$ being linked by additional external $\mathrm{Rb}^{\mathrm{I}}$ cations in $\mathbf{4}$, and complete octanuclear clusters being present in $\mathbf{5}$. The clusters closer to the ideal cubic symmetry are found in the cesium(I)-containing compounds $\left[\left(\mathrm{UO}_{2}\right)_{4} \mathrm{Cs}_{4}(\mathrm{chdc})_{6}\left(\mathrm{H}_{2} \mathrm{O}\right)_{3}\right] \cdot \mathrm{H}_{2} \mathrm{O}(\mathbf{6})$ and $\left[\left(\mathrm{UO}_{2}\right)_{4} \mathrm{Cs}_{4}(R \text {-chdc })_{6}\left(\mathrm{H}_{2} \mathrm{O}\right)_{4}\right] \cdot 3 \mathrm{H}_{2} \mathrm{O}(7)$. In contrast to $\mathbf{1}$, which has fourfold roto-inversion symmetry, $\mathbf{6}$ is a mixture of homochiral clusters with threefold rotation symmetry, thus showing countercation dependence of the isomeric form in the racemic species. In compounds 3-6, multiple bonding of the alkali metal ions to the uranyl oxo groups located inside the cage probably contribute to the cluster stability.
\end{abstract}




\section{INTRODUCTION}

Polynuclear uranyl-containing closed species, whether they be tubules, ${ }^{1-11}$ cages ${ }^{9,12-21}$ or simply large rings, ${ }^{14,22,23}$ are appealing not only for esthetic reasons, but also because they go against the general propensity of the uranyl cation to generate quasi-planar assemblies, as most often observed in uranyl-organic coordination polymers. ${ }^{24-26}$ To ensure closure around a central cavity, the equatorial ligands on the uranyl centres have to provide the required curvature, and this can be achieved with a variety of anions, from the simplest such as peroxides ${ }^{12,17-21}$ to more complicated ones such as polytopic organic ligands. Among the latter, carboxylates are, together with phosphonates, the most commonly used, and closed species have been obtained from mono- ${ }^{23} \mathrm{di}-$ ,${ }^{7,8,12,13,15}$ tri-,${ }^{9,10,11,14}$ tetra- ${ }^{16,22}$ and pentacarboxylates. ${ }^{16}$ The size of the formed species, and consequently of the encompassed cavity, varies widely, from very large in nanospheres ${ }^{16-21}$ down to that of species whose inner spaces are insufficient for any practical use involving encapsulation of guest molecules or ions, but which are nevertheless of interest for the insight they provide about the geometric features allowing formation of closed motifs. ${ }^{9,11}$ During an investigation of complexes formed by uranyl ions with racemic or $(1 R, 2 R)$ enantiopure trans-1,2cyclohexanedicarboxylic acid ( $\mathrm{H}_{2} \mathrm{chdc}$ and $R$ - $\mathrm{H}_{2}$ chdc, respectively), we have recently found that, in the presence of $\mathrm{Na}^{\mathrm{I}}, \mathrm{Ag}^{\mathrm{I}}$ or $\mathrm{Pb}^{\mathrm{II}}$ cations, anionic uranyl tetrahedral clusters $\left[\left(\mathrm{UO}_{2}\right)_{4}((R-) \text { chdc })_{6}\right]^{4-}$ (in which $(R-) \mathrm{chdc}^{2-}$ denotes either of the two forms, racemic or enantiopure, of the dianionic ligand) are readily formed, which are assembled into three-dimensional (3D) frameworks by bridging counterions. ${ }^{27}$ Although such simple cage-like small clusters are rare in the chemistry of the linear uranyl ion, they are more common with the spherical uranium(IV) ions, for which $\mu_{4-}$ oxo-centered tetrahedra are known, ${ }^{28,29}$ as well as cubane geometries. ${ }^{28}$ Tetrahedral clusters $\mathrm{M}_{4} \mathrm{~L}_{6}$ where $\mathrm{M}$ is a main group or transition metal ion have been widely investigated ${ }^{30-40}$ as cages capable 
of selective guest incorporation and selective reaction catalysis, and the principles governing their formation have been clearly enunciated. ${ }^{31,37}$ The stereochemistry of such systems is very dependent upon the chirality of the metal ion centres, ${ }^{31,32,35,41-44}$ a feature which is lost in systems involving the inherently achiral $\left[\mathrm{UO}_{2}\left(\mathrm{O}_{2} \mathrm{CR}\right)_{3}\right]^{-}$centre as the tetrahedron vertices. This places greater importance on the bridging ligands as a source of chirality and on the possibility of isomerism where a chiral ligand is used in its racemic form. Thus, with the aim to further explore the conditions in which the $\left[\left(\mathrm{UO}_{2}\right)_{4}((R-) \text { chdc })_{6}\right]^{4-}$ tetrahedral uranyl clusters are formed and the exact cluster stereochemistry, we replaced $\mathrm{Na}^{\mathrm{I}}$ by other alkali cations $\left(\mathrm{K}^{\mathrm{I}}, \mathrm{Rb}^{\mathrm{I}}, \mathrm{Cs}^{\mathrm{I}}\right)$ and also by an alkaline-earth cation $\left(\mathrm{Ba}^{\mathrm{II}}\right)$, with the expectation that changes in cation size and electronegativity would lead to modifications of the association mode between the anionic cage and the counterions, or even to the formation of different uranyl-containing motifs. We have thus obtained a series of seven compounds which ultimately all contain the tetrahedral uranyl motif, but with different arrangements of the counterions leading in some cases to complete or incomplete cuboidal heterometallic arrangements; the complex formed in the presence of the non-metallic $\mathrm{NH}_{4}{ }^{+}$cation, which is bound through multiple hydrogen bonding interactions, is also reported.

\section{EXPERIMENTAL SECTION}

Syntheses. Caution! Uranium is a radioactive and chemically toxic element, and uraniumcontaining samples must be handled with suitable care and protection.

$\mathrm{UO}_{2}\left(\mathrm{NO}_{3}\right)_{2} \cdot 6 \mathrm{H}_{2} \mathrm{O}$ (depleted uranium, R. P. Normapur, $99 \%$ ), $\mathrm{KNO}_{3}$ and $\mathrm{Ba}\left(\mathrm{NO}_{3}\right)_{2}$ were purchased from Prolabo, $\mathrm{CsNO}_{3}$ was from Acros, $\mathrm{RbNO}_{3}$ from Aldrich, and rac-trans-1,2cyclohexanedicarboxylic acid $\left(\mathrm{H}_{2} \mathrm{chdc}\right)$ was from Lancaster. Elemental analyses were performed by MEDAC Ltd. at Chobham, UK. The $(1 R, 2 R)$ enantiomer of $\mathrm{H}_{2} \mathrm{chdc}$, denoted $R-\mathrm{H}_{2} \mathrm{chdc}$, was 
isolated through crystallization with $(R)$-1-phenylethylamine as a resolving agent, as in the literature ${ }^{45}$ although both the $(1 R, 2 R)$ and $(1 S, 2 S)$ enantiomers are also available commercially. $\left[\mathrm{NH}_{4}\right]_{4}\left[\left(\mathrm{UO}_{2}\right)_{4}(\mathrm{chdc})_{6}\right](\mathbf{1}) . \mathrm{H}_{2} \mathrm{chdc}(17 \mathrm{mg}, 0.10 \mathrm{mmol}), \mathrm{UO}_{2}\left(\mathrm{NO}_{3}\right)_{2} \cdot 6 \mathrm{H}_{2} \mathrm{O}(35 \mathrm{mg}, 0.07$ mmol), guanidinium nitrate $(24 \mathrm{mg}, 0.20 \mathrm{mmol})$, acetonitrile $(0.3 \mathrm{~mL})$, and demineralized water $(0.5 \mathrm{~mL})$ were placed in a $10 \mathrm{~mL}$ tightly closed glass vessel and heated at $150{ }^{\circ} \mathrm{C}$ under autogenous pressure, giving light yellow crystals of compound 1 within two weeks (6 mg, 16\% yield). Anal. calcd for $\mathrm{C}_{48} \mathrm{H}_{76} \mathrm{~N}_{4} \mathrm{O}_{32} \mathrm{U}_{4}$ : C, 26.53; H, 3.52; N, 2.58. Found: C, 26.42; H, 3.15; N, $2.67 \%$. $\left[\left(\mathrm{UO}_{2}\right)_{4} \mathrm{~K}_{4}(R-c h d c)_{6}\left(\mathrm{H}_{2} \mathrm{O}\right)_{6}\right](2) . R-\mathrm{H}_{2} \mathrm{chdc}(17 \mathrm{mg}, 0.10 \mathrm{mmol}), \mathrm{UO}_{2}\left(\mathrm{NO}_{3}\right)_{2} \cdot 6 \mathrm{H}_{2} \mathrm{O}(35 \mathrm{mg}$, $0.07 \mathrm{mmol}), \mathrm{KNO}_{3}(15 \mathrm{mg}, 0.15 \mathrm{mmol}), N$-methyl-2-pyrrolidone $(0.2 \mathrm{~mL})$, and demineralized water $(0.5 \mathrm{~mL})$ were placed in a $10 \mathrm{~mL}$ tightly closed glass vessel and heated at $150{ }^{\circ} \mathrm{C}$ under autogenous pressure, giving light yellow crystals of compound $\mathbf{2}$ in low yield within one week.

$$
\left[\mathrm{H}_{2} \mathrm{NMe}_{2}\right]\left[\left(\mathrm{UO}_{2}\right)_{4} \mathrm{Rb}_{3}(\mathrm{R}-\mathrm{chdc})_{6}\left(\mathrm{H}_{2} \mathrm{O}\right)_{1.75}\right] \quad(3) . \quad R-\mathrm{H}_{2} \mathrm{chdc} \quad(17 \quad \mathrm{mg}, \quad 0.10 \quad \mathrm{mmol}),
$$

$\mathrm{UO}_{2}\left(\mathrm{NO}_{3}\right)_{2} \cdot 6 \mathrm{H}_{2} \mathrm{O}(35 \mathrm{mg}, 0.07 \mathrm{mmol}), \mathrm{RbNO}_{3}(20 \mathrm{mg}, 0.14 \mathrm{mmol}), N, N$-dimethylformamide $(0.2$ $\mathrm{mL})$, and demineralized water $(0.6 \mathrm{~mL})$ were placed in a $10 \mathrm{~mL}$ tightly closed glass vessel and heated at $150{ }^{\circ} \mathrm{C}$ under autogenous pressure, giving light yellow crystals of compound $\mathbf{3}$ within one week (10 mg, 24\% yield). Elemental analysis results are consistent with the presence of one DMF molecule per complex molecule, in keeping with the presence of voids in the crystal lattice, this molecule being probably highly disordered. Anal. calcd for $\mathrm{C}_{50} \mathrm{H}_{71.5} \mathrm{NO}_{33.75} \mathrm{Rb}_{3} \mathrm{U}_{4}+\mathrm{DMF}$ : $\mathrm{C}$, 25.38; H, 3.15; N, 1.12. Found: C, 25.30; H, 2.96; N, 1.23\%.

$\left[\left(\mathrm{UO}_{2}\right)_{4} \mathrm{Rb}_{4}(\mathrm{R}-\mathrm{chdc})_{6}(\mathrm{NMP})_{0.5}\left(\mathrm{H}_{2} \mathrm{O}\right)_{3.75}\right] \cdot 0.5 \mathrm{NMP} \cdot 0.25 \mathrm{H}_{2} \mathrm{O}$ (4). $\mathrm{R}-\mathrm{H}_{2} \mathrm{chdc}(17 \mathrm{mg}, 0.10$ mmol), $\mathrm{UO}_{2}\left(\mathrm{NO}_{3}\right)_{2} \cdot 6 \mathrm{H}_{2} \mathrm{O}(35 \mathrm{mg}, 0.07 \mathrm{mmol}), \mathrm{RbNO}_{3}(20 \mathrm{mg}, 0.14 \mathrm{mmol}$ ), N-methyl-2pyrrolidone $(0.2 \mathrm{~mL})$, and demineralized water $(0.5 \mathrm{~mL})$ were placed in a $10 \mathrm{~mL}$ tightly closed 
glass vessel and heated at $150{ }^{\circ} \mathrm{C}$ under autogenous pressure, giving light yellow crystals of compound 4 in low yield within one week.

$$
\left[\left(\mathrm{UO}_{2}\right)_{4} \mathrm{Rb}_{4}(\mathrm{R}-\mathrm{chdc})_{6}\left(\mathrm{H}_{2} \mathrm{O}\right)_{1.5}\right] \cdot 0.5 \mathrm{H}_{2} \mathrm{O} \quad(5) . \quad R-\mathrm{H}_{2} \mathrm{chdc} \quad(17 \quad \mathrm{mg}, \quad 0.10 \quad \mathrm{mmol}),
$$
$\mathrm{UO}_{2}\left(\mathrm{NO}_{3}\right)_{2} \cdot 6 \mathrm{H}_{2} \mathrm{O}(35 \mathrm{mg}, 0.07 \mathrm{mmol}), \mathrm{RbNO}_{3}(20 \mathrm{mg}, 0.14 \mathrm{mmol})$, methanol $(0.2 \mathrm{~mL})$, and demineralized water $(0.7 \mathrm{~mL})$ were placed in a $10 \mathrm{~mL}$ tightly closed glass vessel and heated at 150 ${ }^{\circ} \mathrm{C}$ under autogenous pressure, giving light yellow crystals of compound $\mathbf{5}$ in low yield within two months.

$\left[\left(\mathrm{UO}_{2}\right)_{4} \mathrm{Cs}_{4}(\mathrm{chdc})_{6}\left(\mathrm{H}_{2} \mathrm{O}\right)_{3}\right] \cdot \mathrm{H}_{2} \mathrm{O}(6) . \mathrm{H}_{2} \mathrm{chdc}(17 \mathrm{mg}, 0.10 \mathrm{mmol}), \mathrm{UO}_{2}\left(\mathrm{NO}_{3}\right)_{2} \cdot 6 \mathrm{H}_{2} \mathrm{O}(35$ $\mathrm{mg}, 0.07 \mathrm{mmol}), \mathrm{CsNO}_{3}(20 \mathrm{mg}, 0.10 \mathrm{mmol})$, methanol $(0.2 \mathrm{~mL})$, and demineralized water $(0.7$ $\mathrm{mL}$ ) were placed in a $10 \mathrm{~mL}$ tightly closed glass vessel and heated at $150{ }^{\circ} \mathrm{C}$ under autogenous pressure, giving light yellow crystals of compound 6 within one month (22 mg, $48 \%$ yield). Anal. calcd for $\mathrm{C}_{48} \mathrm{H}_{68} \mathrm{Cs}_{4} \mathrm{O}_{36} \mathrm{U}_{4}$ : C, 21.32; H, 2.53. Found: C, 21.06; H, 2.39\%.

$\left[\left(\mathrm{UO}_{2}\right)_{4} \mathrm{Cs}_{4}(\mathrm{R}-\mathrm{chdc})_{6}\left(\mathrm{H}_{2} \mathrm{O}\right)_{4}\right] \cdot 3 \mathrm{H}_{2} \mathrm{O}(7) . \mathrm{R}-\mathrm{H}_{2} \mathrm{chdc}(17 \mathrm{mg}, 0.10 \mathrm{mmol}), \mathrm{UO}_{2}\left(\mathrm{NO}_{3}\right)_{2} \cdot 6 \mathrm{H}_{2} \mathrm{O}$ (35 mg, $0.07 \mathrm{mmol}), \mathrm{CsNO}_{3}(20 \mathrm{mg}, 0.10 \mathrm{mmol})$, methanol $(0.2 \mathrm{~mL})$, and demineralized water $(0.6 \mathrm{~mL})$ were placed in a $10 \mathrm{~mL}$ tightly closed glass vessel and heated at $150{ }^{\circ} \mathrm{C}$ under autogenous pressure, giving light yellow crystals of compound 7 within one week (5 mg, 10\% yield). Anal. calcd for $\mathrm{C}_{48} \mathrm{H}_{74} \mathrm{Cs}_{4} \mathrm{O}_{39} \mathrm{U}_{4}$ : C, 20.90; H, 2.70. Found: C, 20.48; H, 2.64\%. $\left[\left(\mathrm{UO}_{2}\right)_{4} \mathrm{Ba}_{2}(\mathrm{R}-\mathrm{chdc})_{6}\left(\mathrm{H}_{2} \mathrm{O}\right)_{8}\right](8) . R-\mathrm{H}_{2} \mathrm{chdc}(17 \mathrm{mg}, 0.10 \mathrm{mmol}), \mathrm{UO}_{2}\left(\mathrm{NO}_{3}\right)_{2} \cdot 6 \mathrm{H}_{2} \mathrm{O}(35 \mathrm{mg}$, $0.07 \mathrm{mmol}), \mathrm{Ba}\left(\mathrm{NO}_{3}\right)_{2}(26 \mathrm{mg}, 0.10 \mathrm{mmol})$, methanol $(0.2 \mathrm{~mL})$, and demineralized water $(0.6 \mathrm{~mL})$ were placed in a $10 \mathrm{~mL}$ tightly closed glass vessel and heated at $150{ }^{\circ} \mathrm{C}$ under autogenous pressure, giving light yellow crystals of compound $\mathbf{8}$ in low yield within two months. 
Crystallography. The data were collected at 150(2) K on a Nonius Kappa-CCD area detector diffractometer ${ }^{46}$ using graphite-monochromated Mo $\mathrm{K} \alpha$ radiation $(\lambda=0.71073 \AA)$. The crystals were introduced into glass capillaries with a protective coating of Paratone-N oil (Hampton Research). The unit cell parameters were determined from ten frames, then refined on all data. The data (combinations of $\varphi$ - and $\omega$-scans with a minimum redundancy of at least 4 for $90 \%$ of the reflections) were processed with HKL2000. ${ }^{47}$ Absorption effects were corrected empirically with the program SCALEPACK. ${ }^{47}$ The structures were solved by direct methods with SHELXS ${ }^{48}$ or by intrinsic phasing with SHELXT, ${ }^{49}$ expanded by subsequent difference Fourier synthesis and refined by full-matrix least-squares on $F^{2}$ with SHELXL-2014. ${ }^{50}$ All non-hydrogen atoms were refined with anisotropic displacement parameters, with restraints being applied for some badly resolved parts, particularly the ammonium counterions in $\mathbf{3}$, or solvent molecules. Two- and threecomponent twinning in $\mathbf{1}$ and $\mathbf{8}$, respectively, was detected with TwinRotMat (PLATON ${ }^{51}$ ) and was taken into account in the refinement. In compound 3, one of the $\mathrm{H}_{2} \mathrm{NMe}_{2}{ }^{+}$cations was given an occupancy factor of 0.5 for charge equilibrium and also to retain acceptable displacement parameters. Some coordinated or free water molecules in compounds $\mathbf{2 - 4 , 6}$ and $\mathbf{7}$, as well as NMP molecules in $\mathbf{4}$, were given half-occupancy in order to retain acceptable displacement parameters and/or to account for too close contacts with their image by symmetry (some of them being further disordered in $\mathbf{4}$ and $\mathbf{6}$ ). The hydrogen atoms bound to oxygen or nitrogen atoms were retrieved from difference Fourier maps when possible, but none was found for compounds 2, 4 and 5; the carbon-bound hydrogen atoms were introduced at calculated positions. All hydrogen atoms were treated as riding atoms with an isotropic displacement parameter equal to 1.2 times that of the parent atom (1.5 for $\mathrm{CH}_{3}$, with optimized geometry). Crystal data and structure refinement parameters are given in Table 1. The molecular plots were drawn with ORTEP- $3^{52}$ and the polyhedral representations with VESTA. ${ }^{53}$ 
Luminescence Measurements. Emission spectra were recorded on solid samples using a Horiba-Jobin-Yvon Fluorolog spectrofluorometer. The powdered compound was pressed between two silica plates which were mounted such that the faces were oriented vertically and at $45^{\circ}$ to the incident excitation radiation. An excitation wavelength of $420 \mathrm{~nm}$, a commonly used point although only part of a broad manifold, was used in all cases and the emission was monitored between 450 and $650 \mathrm{~nm}$.

\section{RESULTS AND DISCUSSION}

Synthesis. All compounds 1-8 were synthesized under solvo-hydrothermal conditions (150 ${ }^{\circ} \mathrm{C}$ ). Different organic cosolvents were tried in each case, those finally giving crystals suitable for X-ray diffraction being acetonitrile (1), $N, N$-dimethylformamide (3), $N$-methyl-2-pyrrolidone (2 and 4) and methanol (5-8). It is notable that oligomerization through oxo/hydroxo bridges resulting from hydrolysis is completely absent in this series of complexes. The $\mathrm{NH}_{4}{ }^{+}$counterions in $\mathbf{1}$ were generated in situ, probably from acetonitrile hydrolysis possibly catalyzed by $\mathrm{U}^{\mathrm{VI}}$, as previously observed, ${ }^{11,54}$ while the formation of $\mathrm{H}_{2} \mathrm{NMe}_{2}{ }^{+}$cations in $\mathbf{3}$ results from DMF hydrolysis, a very frequent occurrence when this solvent is used at elevated temperatures in the presence of metal ions, as in solvo-hydrothermal syntheses. ${ }^{55}$ The rate of these solvent hydrolysis reactions may be a factor limiting the yields of the compounds in these cases. The organic cosolvent is retained as a coligand in complex $\mathbf{4}$ only, but its importance, even in cases in which it is absent in the final compound, is well illustrated by complex 7: when the same experiment is performed in pure water, the previously reported complex $\left[\mathrm{UO}_{2}(R\right.$-chdc) $)(\mathbf{9})$, which crystallizes as a two-dimensional assembly, ${ }^{27}$ is obtained instead. The solvent effect is also notable for the three rubidium-containing species 3-5 since one rubidium cation is replaced by the solvent-generated $\mathrm{H}_{2} \mathrm{NMe}_{2}{ }^{+}$cation in $\mathbf{3}$, 
and a coordinated NMP molecule is present in $\mathbf{4}$, the complex with the simplest formula, $\mathbf{5}$, being obtained with methanol as cosolvent. As previously noticed, the chirality of the ligand appears to have little effect on the ease of formation of the tetranuclear cluster, although this is not true in relation to the exact symmetry of the cluster or more generally of the reaction of $(R-) \operatorname{chdc}^{2-}$ with uranyl ions, ${ }^{27}$ but it is notable that most complexes in the present series contain the enantiopure $R$ chdc $^{2-}$ ligand (which appears to be stable to inversion under the reaction conditions employed), thus possibly indicating readier crystallization in this case. While it proved possible to grow crystals with all common alkali metal cations except $\mathrm{Li}^{\mathrm{I}}$, for which only crystals of the formerly described complex 9 were obtained, alkaline-earth cations are much less tractable and only in the case of $\mathrm{Ba}^{\mathrm{II}}$ was a complex crystallized, the common outcome of the reaction otherwise being either formation of complex 9 or of amorphous precipitates, or of no solid species.

Crystal Structures. Given the use of $\operatorname{chdc}^{2-}$ in both its racemic and resolved $(R, R)$ forms and the fact that all the complexes presently described contain a pseudo-tetrahedral cluster of four uranyl ions, it is relevant to consider the isomerism possible when the edges of a tetrahedron are spanned by different ligands. The simplest instance is that where two symmetrical, achiral, ditopic ligands $\mathrm{A}$ and $\mathrm{B}$ are involved (Scheme 1). Formation of a tetrahedral cluster from a metal ion $\mathrm{M}$ and a mixture of such ligands A and B capable of spanning each of the six tetrahedral edges could lead to an isomeric mixture of considerable complexity. While the species $\mathrm{M}_{4} \mathrm{~A}_{6}\left(\equiv \mathrm{M}_{4} \mathrm{~B}_{6}\right)$ and $\mathrm{M}_{4} \mathrm{~A}_{5} \mathrm{~B}\left(\equiv \mathrm{M}_{4} \mathrm{AB}_{5}\right)$ have only one form, both $\mathrm{M}_{4} \mathrm{~A}_{4} \mathrm{~B}_{2}\left(\equiv \mathrm{M}_{4} \mathrm{~A}_{2} \mathrm{~B}_{4}\right)$ and $\mathrm{M}_{4} \mathrm{~A}_{3} \mathrm{~B}_{3}$ have two, but in the latter case one of these is chiral so that it would exist as two enantiomers. Where A and B become enantiomeric species such as $R$ - and $S$ - $\operatorname{chdc}^{2-}$ (viz. if the racemic acid is used to synthesise the cluster), $\mathrm{M}_{4} \mathrm{~A}_{6}$ is simply the enantiomer of $\mathrm{M}_{4} \mathrm{~B}_{6}, \mathrm{M}_{4} \mathrm{~A}_{5} \mathrm{~B}$ the enantiomer of $\mathrm{M}_{4} \mathrm{AB}_{5}$, and the 
two forms of $\mathrm{M}_{4} \mathrm{~A}_{4} \mathrm{~B}_{2} / \mathrm{M}_{4} \mathrm{~A}_{2} \mathrm{~B}_{4}$ become two enantiomer pairs. The achiral form of $\mathrm{M}_{4} \mathrm{~A}_{3} \mathrm{~B}_{3}$ becomes an enantiomer pair ( $C_{3}$ symmetry), but the chiral form becomes achiral ( $S_{4}$ symmetry) since it contains two chiral subunits, $\mathrm{M}_{4} \mathrm{~A}_{3}$ and $\mathrm{M}_{4} \mathrm{~B}_{3}$, that are mirror images of one another, their combination being thus achiral. Since each of these chiral subunits in the $\mathrm{M}_{4} \mathrm{~A}_{3} \mathrm{~B}_{3}$ achiral species is associated to a different handedness, a pair of diastereomers is generated by permutation of A and B (i.e. $R$ - and $S$-chdc ${ }^{2-}$ ), the two members of the pair corresponding to the two different $R$ - and $S$-chdc ${ }^{2-} /$ right- and left-handed combinations.

The compound $\left[\mathrm{NH}_{4}\right]_{4}\left[\left(\mathrm{UO}_{2}\right)_{4}(\mathrm{chdc})_{6}\right](\mathbf{1})$ is the simplest case illustrating the formation of the uranyl pseudotetrahedral cage, since it is devoid of additional metal cations, and it provides a useful example of the consequence of the use of the racemic ligand as reactant which can be related to our earlier work based on similar syntheses. Complex 1 crystallizes in the same tetragonal space group $I 4_{1} / a$ as the complexes $\left[\left(\mathrm{UO}_{2}\right)_{4} \mathrm{Na}_{4}(\mathrm{chdc})_{6}\left(\mathrm{H}_{2} \mathrm{O}\right)_{4}\right](\mathbf{1 0})$ and $\left[\left(\mathrm{UO}_{2}\right)_{4} \mathrm{Ag}_{4}(\mathrm{chdc})_{6}\left(\mathrm{H}_{2} \mathrm{O}\right)_{4}\right](\mathbf{1 1})$, previously described, ${ }^{27}$ and with unit cell parameters not very different from theirs. The disorder present in the structure of $\mathbf{1 0}$ is absent in that of $\mathbf{1}$, as it is in that of $\mathbf{1 1}$, so that the isomeric form of the cluster is established in $\mathbf{1}$ and $\mathbf{1 1}$ as that of an $\left[\left(\mathrm{UO}_{2}\right)_{4}(R \text {-chdc })_{3}(S \text {-chdc })_{3}\right]^{4-}$ anion with $S_{4}$ symmetry (i.e. the form shown in Scheme 1 as two enantiomers when A and B are constitutionally different). The asymmetric unit contains one uranyl cation and two chdc ${ }^{2-}$ ligands, one of them located on a twofold rotation axis. The uranyl cation is chelated by three carboxylate groups from three ligands (Figure 1); the $\mathrm{U}-\mathrm{O}(\mathrm{oxo})$ bond lengths of 1.766(5) and 1.767(5) $\AA$, and the $\mathrm{U}_{-}$ $\mathrm{O}$ (carboxylate) bond lengths, in the range of 2.417(6)-2.521(6) $\AA$ [average 2.48(3) $\AA$ ], are unexceptional. The pseudotetrahedral assembly formed is very similar to those in compounds $\mathbf{1 0}$ and 11, and close to those in the previously studied enantiopure compounds $\left[\left(\mathrm{UO}_{2}\right)_{4} \mathrm{Na}_{4}(R-\right.$ chdc $\left.)_{6}\left(\mathrm{H}_{2} \mathrm{O}\right)_{4}\right](\mathbf{1 2})$ and $\left[\left(\mathrm{UO}_{2}\right)_{4} \mathrm{~Pb}_{2}(R \text {-chdc })_{6}\left(\mathrm{H}_{2} \mathrm{O}\right)_{8}\right](\mathbf{1 3}),{ }^{27}$ although with significant differences in stereochemistry. Thus, the $\left[\left(\mathrm{UO}_{2}\right)_{4}(\mathrm{chdc})_{6}\right]^{4-}$ motif admits a fourfold roto-inversion axis as 
symmetry element, consistent with the (chdc $)_{6}$ component actually being $(R \text {-chdc })_{3}(S \text {-chdc })_{3}($ see above), the particular diastereomer formed being $\Lambda$ - $R$-chdc, $\Delta-S$-chdc, and there are four short and two long intra-cage U...U distances, 5.8185(5) $\AA$ and 6.9163(6) $\AA$, respectively. The four ammonium counterions are located above the four faces of the tetrahedron, and they form three hydrogen bonds with three carboxylate oxygen atoms from one cage and one with a carboxylate

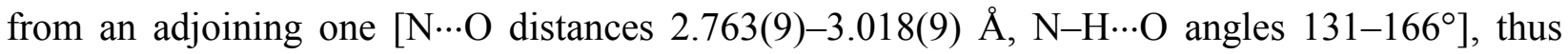
forming a 3D hydrogen bond network. The 3D nature of this assembly is presumably a factor favouring the incorporation of ammonium ion in the crystal rather than the planar guanidinium ion also present in the reaction mixture. Ammonium ion is sometimes designated as a "pseudo-metal ion" having properties similar to potassium ion ${ }^{56}$ and although the actual nature of the interactions is different, the triple hydrogen bonding interactions of ammonium with the uranyl cluster are dimensionally very similar to the bonds with $\mathrm{K}^{\mathrm{I}}$ (see below). Since four uranyl oxo groups which could possibly act as hydrogen bond acceptors are directed toward the centre of the cage, inclusion of a fourfold hydrogen bond donor ( such as $\mathrm{NH}_{4}{ }^{+}$) would in principle be possible, but it is precluded by the too small cavity size. ${ }^{27}$ The Kitaigorodski packing index (KPI, estimated with PLATON ${ }^{51}$ ) is 0.68 , a value indicative of a compact arrangement leaving no solvent-accessible free space.

In keeping with the presence of the enantiopure ligand, $\left[\left(\mathrm{UO}_{2}\right)_{4} \mathrm{~K}_{4}(R \text {-chdc })_{6}\left(\mathrm{H}_{2} \mathrm{O}\right)_{6}\right](2)$ crystallizes in the tetragonal Sohnke space group $I_{1} 22$, while its $\mathrm{Na}^{\mathrm{I}}$ counterpart 12 crystallizes in $I 4_{1}$, with slightly different unit cell parameters. The asymmetric unit contains one uranyl and one $\mathrm{K}^{\mathrm{I}}$ cation, and three ligands located on twofold rotation axes (Figure 2). The uranium ion environment is similar to that in $\mathbf{1}$, with $\mathrm{U}-\mathrm{O}$ (oxo) bond lengths of 1.758(13) and 1.762(13) $\AA$ and U-O(carboxylate) bond lengths of 2.458(14)-2.489(15) $\AA$ [average 2.477(10) $\AA$ ]. Possibly due to the presence of but one ligand enantiomer in the cluster, the $\left[\left(\mathrm{UO}_{2}\right)_{4}(R \text {-chdc })_{6}\right]^{4-}$ cage is less 
distorted than in 1, the U...U distances being 6.2420(14), 6.2947(16) and 6.4218(15) $\AA$. The potassium atom, in a very irregular environment, is bound to the two carboxylate oxygen atoms $\mathrm{O} 4$ and $\mathrm{O} 5$ from one cage, and to $\mathrm{O} 7$ from an adjacent one, with $\mathrm{K}-\mathrm{O}$ bond lengths of 2.613(17)2.693(19) $\AA$, and to four bridging water molecules (two of them on half-occupied sites, see Experimental Section) at 2.39(3)-2.97(4) $\AA$; two longer contacts with the carboxylate oxygen atoms $\mathrm{O}^{\mathrm{m}}$ and $\mathrm{O}^{\mathrm{n}}$, at 3.34(2) and 3.107(16) $\AA$, respectively, may represent weaker interactions at best. Even if the latter contacts are disregarded, bridging by potassium atoms results in the formation of a 3D framework, as in the case of the sodium-containing compound (KPI 0.74). The fact that both ammonium and potassium derivatives of the anionic cluster can be crystallised reflects commonly encountered similarities in the solubility of analogous potassium and ammonium compounds $^{56}$ and, as noted above, the mean $\mathrm{N} \cdots \mathrm{O}$ and $\mathrm{K}-\mathrm{O}$ distances in $\mathbf{1}$ and $\mathbf{2}$ are indeed rather similar.

Three complexes were obtained with rubidium(I) as additional cation, $\left[\mathrm{H}_{2} \mathrm{NMe}_{2}\right]\left[\left(\mathrm{UO}_{2}\right)_{4} \mathrm{Rb}_{3}(R \text {-chdc })_{6}\left(\mathrm{H}_{2} \mathrm{O}\right)_{1.75}\right] \quad(3), \quad\left[\left(\mathrm{UO}_{2}\right)_{4} \mathrm{Rb}_{4}(R \text {-chdc })_{6}(\mathrm{NMP})_{0.5}\left(\mathrm{H}_{2} \mathrm{O}\right)_{3.75}\right] \cdot 0.5 \mathrm{NMP}$. $0.25 \mathrm{H}_{2} \mathrm{O}(4)$ and $\left[\left(\mathrm{UO}_{2}\right)_{4} \mathrm{Rb}_{4}(R-\mathrm{chdc})_{6}\left(\mathrm{H}_{2} \mathrm{O}\right)_{1.5}\right] \cdot 0.5 \mathrm{H}_{2} \mathrm{O}(5)$, which all contain the enantiopure ligand and crystallize in the Sohncke space groups $C 2, P 2_{1}$ and $R 32$, respectively. The asymmetric unit in 3 contains four uranium and three rubidium atoms, and six complete ligands (Figure 3). All uranyl cations are tris-chelated, and the U-O(oxo) bond lengths, $1.746(14)-1.789(15) \AA$, and the U-O(carboxylate) bond lengths, 2.404(16)-2.520(15) $\AA$ [average 2.46(3) $\AA$ ], are as usual. The pseudotetrahedral cage is here also less distorted than in 1, with $\mathrm{U} \cdots \mathrm{U}$ distances in the range of 6.2016(11)-6.3775(14) A. A search of the Cambridge Structural Database (CSD, Version 5.38) ${ }^{57}$ for $\mathrm{Rb}-\mathrm{O}$ bond lengths reveals a very large and asymmetric distribution ranging from $\sim 2.7$ to $\sim 3.5$ $\AA$ (excluding a few outliers), so that contacts within this range will be considered here. All three 
$\mathrm{Rb}^{\mathrm{I}}$ ions are bound to six carboxylate groups pertaining to the same cage unit, with $\mathrm{Rb}-\mathrm{O}$ bond lengths of 2.941(13)-3.42(2) $\AA$ [average 3.17(14) $\AA$ ], and to none from adjacent units; they are also bound to bridging water molecules, some of them badly resolved (see Experimental Section), with $\mathrm{Rb}-\mathrm{O}$ bond lengths of 2.75(4)-3.02(3) $\AA$. Each rubidium atom makes also three contacts with uranyl oxo groups located inside the cavity, with $\mathrm{Rb}-\mathrm{O}$ (oxo) bond lengths of 3.079(13)-3.287(16) $\AA$ [average 3.18(7) $\AA$, similar to that with carboxylate groups]. Uranyl oxo bonding to alkali metal ions is rather frequent and about a dozen cases with $\mathrm{Rb}^{\mathrm{I}}$ are found in the CSD; the $\mathrm{Rb}-\mathrm{O}$ (oxo) bond lengths here are comparable to those of 2.805(10)-3.236(11) $\AA$ found in the complex associated with the widest range reported ${ }^{58}$ but it is however notable that the corresponding $\mathrm{U}-\mathrm{O}$ bonds are not significantly longer than the others, thus indicating that these interactions are not very strong ones. The rubidium approach to the oxo groups is however limited here by the somewhat congested nature of the complex core. The three $\mathrm{Rb}^{\mathrm{I}}$ ions are much closer to the tetrahedron faces than are the potassium ions in $\mathbf{2}$, so that the seven atom centres form a distorted incomplete cuboidal arrangement, as shown in Figure 4. The $\mathrm{U} \cdots \mathrm{Rb}$ distances defining the edges range from 4.016(2) to 4.243(3) $\AA$, and, since the diagonal $\mathrm{Rb} \cdots \mathrm{Rb}$ distances [5.206(4)-5.264(4) $\AA]$ are shorter than the $\mathrm{U} \cdots \mathrm{U}$ ones (see above), the $\mathrm{U} \cdots \mathrm{Rb} \cdots \mathrm{U}$ angles $\left[97.78(6)-100.98(5)^{\circ}\right]$ are larger than the $\mathrm{Rb} \cdots \mathrm{U} \cdots \mathrm{Rb}$ ones [77.61(5)-81.69(5) ${ }^{\circ}$, the smallest values being for the uranium atoms U2, U3 and U4 that have only two rubidium neighbours]. One of the dimethylammonium counterions, located on a twofold rotation axis, is directed toward the open faces of two cuboids and is hydrogen bonded to one carboxylate oxygen atom from each $\left[\mathrm{N} 2 \cdots \mathrm{O} 22\right.$ 3.07(2) $\left.\AA, \mathrm{N} 2-\mathrm{H} \cdots \mathrm{O} 221^{\circ} 0^{\circ}\right]$. Bridging of rubidium cations pertaining to different cuboids by water molecules, that leads to $\mathrm{Rb} \cdots \mathrm{Rb}$ distances of 4.934(3) and 4.941(5) $\AA$ shorter than the intra-cuboid ones, gives rise to the formation of a 2D assembly parallel to $(20-1)$ displaying a hexagonal arrangement of cages, adjacent layers being 
connected to one another by the hydrogen bonded counterions. The disorder affecting some counterions and the probable presence of highly disordered DMF molecules in the voids (see Experimental Section) prevents a more specific analysis of the hydrogen bonding in the lattice, which has a KPI of 0.65 .

The dimethylammonium cation present in $\mathbf{3}$ is replaced by one more rubidium ion in $\mathbf{4}$, in which the asymmetric unit contains twice the $\left(\mathrm{UO}_{2}\right)_{4} \mathrm{Rb}_{4}(R \text {-chdc })_{6}$ motif (Figure 5). There is nothing unusual in the $\mathrm{U}-\mathrm{O}(\mathrm{oxo})[1.736(11)-1.787(11) \AA]$ and $\mathrm{U}-\mathrm{O}$ (carboxylate) bond lengths [2.429(12)-2.511(10) $\AA$, average 2.47(2) $\AA]$. The four uranium atoms in each unit form a pseudotetrahedron, and three rubidium atoms are connected, as their counterparts in $\mathbf{3}$, to six carboxylate oxygen atoms from the same unit [2.870(12)-3.608(15) $\AA$, average 3.2(2) $\AA$, to three uranyl oxo groups [3.030(11)-3.363(13) $\AA$, average 3.19(9) $\AA$, and to one or two water molecules, some of them disordered. In contrast, the fourth rubidium ion in each unit ( $\mathrm{Rb} 4$ and $\mathrm{Rb} 8$ ) does not fill the vacant site of the incomplete cuboid, but adopts a lateral position analogous to that of potassium ions in 2 (Figure 4). These two cations are each bound to four carboxylate oxygen atoms pertaining to two adjacent heptanuclear units, thus making double bridges between the two crystallographically independent cages (Figure 5); they are further bound to partly disordered water and NMP molecules. Other bridges between cages are provided by water molecules, so that overall a 3D framework is generated (KPI 0.69). The cluster formed is thus an incomplete cuboid, as in complex $\mathbf{3}$, with an extra lateral $\mathrm{Rb}^{\mathrm{I}}$ cation. The $\mathrm{U} \cdots \mathrm{Rb}$ distances defining the edges are in the range of 3.9689(18)-4.296(2) $\AA$, and the $\mathrm{U} \cdots \mathrm{U}$ and $\mathrm{Rb} \cdots \mathrm{Rb}$ diagonal distances are 6.2376(9)-6.455(3) $\AA$ and 5.192(3)-5.303(2) Å, respectively, resulting here also in $\mathrm{U} \cdots \mathrm{Rb} \cdots \mathrm{U}$ angles [97.80(4)103.91(4) ${ }^{\circ}$ ] larger than $\mathrm{Rb} \cdots \mathrm{U} \cdots \mathrm{Rb}$ ones $\left[75.24(4)-81.55(4)^{\circ}\right]$. 
Complex 5 represents the next step in the generation of these uranyl-rubidium complexes, in which a complete cuboidal arrangement is achieved. The asymmetric unit contains two uranyl and two rubidium atoms, one of each being located on a threefold rotation axis (Wyckoff position $6 c$ ), and two $R$-chdc ${ }^{2-}$ ligands (Figure 6). The $\mathrm{U}-\mathrm{O}($ oxo) $[1.70(2)-1.75(2) \AA \AA$ and $\mathrm{U}-$ $\mathrm{O}$ (carboxylate) bond lengths [2.42(2)-2.50(2) $\AA$, average 2.46(2) $\AA$ ] are similar to those in 3 and 4. The rubidium atoms are bound to six (Rb1) or five (Rb2) carboxylate donors [2.94(2)-3.49(3) $\AA$ ] and three uranyl oxo groups (all the latter being thus involved in trifurcate interactions) [3.108(19)-3.28(2) $\AA$ ]; one water molecule located on a twofold rotation axis is bridging rubidium atoms of adjacent clusters [Rb2-O13 2.772(10) Å, leading to a separation of 4.846(10) $\AA$ between the metal centres]. The $\mathrm{Rb} \cdots \mathrm{Rb}$ distances in the rubidium tetrahedron [5.160(7) and 5.334(9) $\AA$ ] are here also smaller than the U...U ones in the uranium tetrahedron [6.2869(18) and 6.368(2) $\AA$ ], and the $\mathrm{U} \cdots \mathrm{Rb} \cdots \mathrm{U}$ angles $\left[96.98(10)-104.08(9)^{\circ}\right]$ are larger than $\mathrm{Rb} \cdots \mathrm{U} \cdots \mathrm{Rb}$ ones $[75.92(9)-$ $\left.82.38(10)^{\circ}\right]$. The cuboid edges correspond to $\mathrm{U} \cdots \mathrm{Rb}$ distances of $4.038(3)-4.342(5) \AA$. The presence of the water links results in the formation of a 2D assembly parallel to $\left(\begin{array}{lll}0 & 0 & 1\end{array}\right)$, which displays a hexagonal arrangement of the clusters (KPI 0.62).

In the case of $\mathrm{Cs}^{\mathrm{I}}$, complexes with both racemic and enantiopure ligands could be isolated, $\left[\left(\mathrm{UO}_{2}\right)_{4} \mathrm{Cs}_{4}(\mathrm{chdc})_{6}\left(\mathrm{H}_{2} \mathrm{O}\right)_{3}\right] \cdot \mathrm{H}_{2} \mathrm{O}(6)$ and $\left[\left(\mathrm{UO}_{2}\right)_{4} \mathrm{Cs}_{4}(R \text {-chdc })_{6}\left(\mathrm{H}_{2} \mathrm{O}\right)_{4}\right] \cdot 3 \mathrm{H}_{2} \mathrm{O}(7)$, which crystallize in the centrosymmetric cubic space group $P a-3$ and the orthorhombic Sohncke space group $C 222_{1}$, respectively. The asymmetric unit in $\mathbf{6}$ contains two uranyl and two cesium atoms, one of each located on a threefold rotation axis (Wyckoff position $8 c$ ) and two chdc ${ }^{2-}$ ligands, both with the same chirality (Figure 7). The environment of the uranium atoms is similar to that in the previous complexes [U-O(oxo) 1.741(15)-1.769(7) $\AA$; U-O(carboxylate) 2.437(8)-2.494(7) $\AA$, average 2.464(19) $\AA$, while the cesium atoms are bound to six carboxylate oxygen atoms [3.078(7)- 
3.492(7) $\AA$, average 3.26(12) $\AA$, to be compared to the range of 2.81-3.68 $\AA$, average 3.17(15) $\AA$, for cesium-carboxylate bonds reported in the CSD (140 hits)]. Cs1 is further bound to two water molecules (one of them disordered), at 3.029(17) and 3.57(3) $\AA$ [2.95-3.80 $\AA$, average 3.27(17) $\AA$, from the CSD (82 hits)]. Both cesium atoms are involved in three bonds with uranyl oxo groups, buth those with Cs1 [3.615(8), 3.735(3) and $3.828 \AA]$ are much longer than those with Cs2 [3.399(8) $\AA]$. These values are at the upper end of the range usual for cesium oxo-bonding to uranyl, for which distances of 3.0-3.3 $\AA$ are frequent, ${ }^{5,59,60}$ larger values, up to $3.8 \AA$, having however been reported. ${ }^{61}$ As in complex $\mathbf{5}$, the octanuclear, heterometallic cluster is cuboidal in shape, with edge lengths of 4.2564(8)-4.4918(10) A. However, the distorsion with respect to the ideal cubic geometry is lesser here than in 5, since the diagonal U..U distances [6.2124(7) and 6.3053(7) $\AA$ ] and the Cs $\cdots$ Cs ones [5.9677(16) and 6.3275(16) $\AA]$ are close to one another and, as a consequence, the $\mathrm{Cs} \cdots \mathrm{U} \cdots \mathrm{Cs}$ and $\mathrm{U} \cdots \mathrm{Cs} \cdots \mathrm{U}$ angles $\left[85.982(18)-91.17(2)^{\circ}\right.$ and 88.158(17)-95.58(2) respectively] differ from $90^{\circ}$ by $\sim 5^{\circ}$ at most, instead of $\sim 14^{\circ}$ in $\mathbf{5}$. Due to the absence of cesiumbridging water molecules, $\mathbf{6}$ is a molecular complex, with intermolecular hydrogen bonding involving coordinated water molecules being present (KPI 0.72). While formally a mixed-ligand complex, since it was obtained from the racemic ligand, $\mathbf{6}$ is unlike $\mathbf{1}$ and the earlier described compounds 10 and 11 in that the lattice contains equal numbers of $\left[\left(\mathrm{UO}_{2}\right)_{4}(R \text {-chdc })_{6}\right]^{4-}$ and $\left[\left(\mathrm{UO}_{2}\right)_{4}(S \text {-chdc })_{6}\right]^{4-}$ units, a change necessarily associated with differences in the cation interactions. Thus, the relatively weak and less directional interactions of $\mathrm{Cs}^{\mathrm{I}}$, as well as its larger size, may be considered the cause of a longer distance between cluster centroids than in the $\mathrm{Na}^{\mathrm{I}}$ species (12.2 versus $10.3 \AA$ ), and thus a diminution of ligand $\cdots$ ligand interactions between clusters, although the implication here that an isolated cluster where all ligands are of the same chirality would be more stable than one with mixed enantiomers is not so readily explained. The differences 
are perhaps more likely due to the coordination preferences of the different metal ions and the interactions induced within the clusters (see discussion ahead).

The asymmetric unit in complex 7 contains two uranyl and two cesium ions in general positions, and four $R$-chdc ${ }^{2-}$ ligands, two of which have twofold rotation symmetry (Figure 8 ). The uranium coordination environment is as usual [U-O(oxo) 1.744(9)-1.760(8) Å; U-O(carboxylate) 2.426(9)-2.508(8) $\AA$, average 2.47(2) $\AA$, and both cesium atoms are bound to six carboxylate groups $[3.100(8)-3.402(9) \AA$, average $3.24(10) \AA]$ and to three uranyl oxo groups [3.438(9)3.663(8) $\AA$ ]. Cs2 is bound to only one terminal water molecule, at 3.241(14) $\AA$, whereas Cs1 is bound to two bridging water molecules, at 2.993(13) and 3.334(15) $\AA$, thus forming $\mathrm{Cs}_{2}\left(\mathrm{H}_{2} \mathrm{O}\right)_{2}$

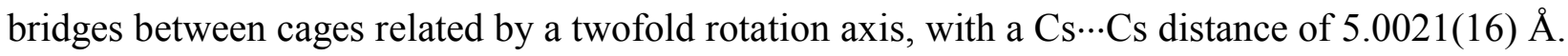

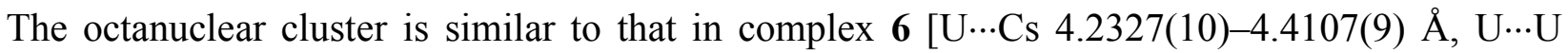

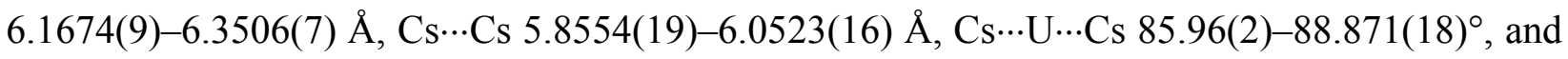

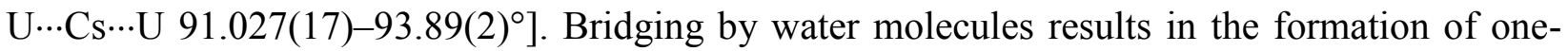
dimensional zigzag polymers running along the $c$ axis, these chains being linked to one another through hydrogen bonding mediated by the free water molecules to form a 3D network (KPI 0.68).

The last complex in the present series, $\left[\left(\mathrm{UO}_{2}\right)_{4} \mathrm{Ba}_{2}(R \text {-chdc })_{6}\left(\mathrm{H}_{2} \mathrm{O}\right)_{8}\right](8)$, is the only one that could be obtained with an alkaline-earth cation. It crystallizes in the chiral tetragonal space group $\mathrm{P}_{3}{ }_{3}{ }_{1} 2$ and, since it is isomorphous to the $\mathrm{Pb}^{\mathrm{II}}$-containing compound $\mathbf{1 3},{ }^{27}$ it will be only briefly described. The asymmetric unit contains two uranyl and one barium atoms (Figure 9). The former are in their usual environment [U-O(oxo) 1.757(11)-1.758(12) Å; U-O(carboxylate) 2.417(12)2.562(12) $\AA$, average 2.48(4) $\AA$ ], and the latter, in an eight-coordinate environment of very irregular geometry, is bound to four carboxylate groups pertaining to four ligands from two cages [2.777(12)-2.943(12) $\AA$, average 2.86(7) $\AA$, to be compared to the average of 2.81(12) $\AA$ from the 
CSD (462 hits)] and four water molecules (none of them bridging) [2.626(14)-2.671(13) $\AA$, average 2.653(17) $\AA ; 2.81(9) \AA$ from the CSD (389 hits)]. As with sodium, potassium, silver and lead ions in the formerly described compounds $\mathbf{1 0}-\mathbf{1 3}$, the barium ions are farther than rubidium or cesium from the uranyl tetrahedron faces (Figure 4) and they bridge adjacent tetranuclear cages to form a 3D framework (KPI 0.69).

The anionic $\left[\left(\mathrm{UO}_{2}\right)_{4}((R-) \mathrm{chdc})_{6}\right]^{4-}$ pseudotetrahedron appears to be a prevalent motif in the crystalline complexes formed by uranyl ions with $(R-) \operatorname{chdc}^{2-}$ since it appears in 12 out of the 21 complexes known, and may indeed be the unique form for a ratio $\mathrm{UO}_{2}{ }^{2+} /(R-) \operatorname{chdc}^{2-}$ of $1: 1.5$. In particular, it is found in all cases in which alkali metal ions heavier than lithium are present. Only in the case of complex 1 was this species found in the absence of an additional metal cation. In all other cases, the added cations are bound to carboxylate groups from either one $\left(\mathrm{Rb}^{\mathrm{I}}, \mathrm{Cs}^{\mathrm{I}}\right)$ or two $\left(\mathrm{Na}^{\mathrm{I}}, \mathrm{K}^{\mathrm{I}}, \mathrm{Rb}^{\mathrm{I}}, \mathrm{Ba}^{\mathrm{II}}, \mathrm{Ag}^{\mathrm{I}}, \mathrm{Pb}^{\mathrm{II}}\right)$ tetrahedral cages. In the latter case, they are located far from the tetrahedron faces and serve as bridges between adjacent cages, which are thus united into a higher dimensionality assembly. In the former case, they are closer to the tetrahedron faces and heterometallic heptanuclear incomplete or octanuclear complete cuboid motifs are formed. Rubidium is peculiar since, depending on the synthesis conditions, it is able to adopt one or the other position, as shown in complexes 3-5. Within the alkali metal ion series, there is thus a regular trend, from $\mathrm{Li}^{\mathrm{I}}$, which does not form such a solid state assembly, to $\mathrm{Na}^{\mathrm{I}}$ and $\mathrm{K}^{\mathrm{I}}$, which are mere bridges between tetrahedral cages, $\mathrm{Rb}^{\mathrm{I}}$ that may be bridging or included in distorted incomplete or complete cuboids, and finally $\mathrm{Cs}^{\mathrm{I}}$, which forms complete cuboids little distorted from the ideal cubic geometry, and favours the formation of homochiral clusters rather than the mixed species obtained from the racemic ligand with $\mathrm{NH}_{4}{ }^{+}, \mathrm{Na}^{\mathrm{I}}$ and $\mathrm{Ag}^{\mathrm{I}}$ countercations. Only for alkali ions with the larger radii, and ensuing longer bond lengths, is it possible to build the cuboid motif while retaining the quite rigid geometry of the uranyl tetrahedron. This is in agreement with the 
observations for other cations, since the ionic radius of $\mathrm{Ag}^{\mathrm{I}}$ is close to that of $\mathrm{Na}^{\mathrm{I}}$, that of $\mathrm{Ba}^{\mathrm{II}}$ to that of $\mathrm{K}^{\mathrm{I}}$, and that of $\mathrm{Pb}^{\mathrm{II}}$ is intermediate between them. ${ }^{62}$ However, it may be noted that the $\mathrm{Pb}-$ $\mathrm{O}\left(\right.$ carboxylate) bond lengths in 13 [2.95(2)-3.09(2) $\AA$ ] are comparable to those measured for $\mathrm{Rb}^{\mathrm{I}}$, thus suggesting that other characteristics of the cations, such as charge and affinity for carboxylate ligands, are most certainly also at play here. As we have found in a simpler carboxylate system, ${ }^{63}$ the interactions of $\mathrm{Rb}^{\mathrm{I}}$ and $\mathrm{Cs}^{\mathrm{I}}$ with carboxylates can be rather different to those of the other alkali metals and the highly unsymmetrical nature of the coordination sphere of some of the $\mathrm{Cs}^{\mathrm{I}}$ centres in the present structures is quite striking, although its fundamental origin is not evident. The radius effect may explain why no cluster species could be crystallised with alkaline-earth cations lighter than $\mathrm{Ba}^{\mathrm{II}}$. Another factor that may have a role is the possibility of oxo bonding to uranyl, the distance of the cuboid apexes to these oxo groups being well-matched to the largest alkali cations. As already noted, ${ }^{27}$ the ligand chirality has little impact on the formation and geometry of these cages, as confirmed here by complexes $\mathbf{6}$ and 7 in particular, but the crystallographic symmetry of the cage depends on it, with fourfold roto-inversion symmetry being present in the racemic compounds $\mathbf{1}$ and $\mathbf{1 1}$, so that the cage contains both enantiomers of the ligand, while twofold rotation symmetry is present for the enantiopure cages in $\mathbf{2 , 7 , 8 , 1 2}$ and $\mathbf{1 3}$, threefold rotation symmetry in $\mathbf{5}$, and no symmetry at all in $\mathbf{3}$ and $\mathbf{4}$. However, only a threefold rotation axis is present in the racemic complex $\mathbf{6}$, so that in this case the cages are homochiral, but half the cages in the lattice contain $(R, R)$ and the other half $(S, S)$ ligands. Species obtained from the racemic ligand can thus display a degree of selectivity in their isomeric composition. The formation of these clusters provides a variation on the principles known for the generation of such species ${ }^{31}$ in that the $\mathrm{UO}_{8}$ unit forming the vertices of the cluster is formally achiral while the ligand is chiral and exists in two separable (mirror image) forms. A further distinction from known $\mathrm{M}_{4} \mathrm{~L}_{6}$ clusters is that the uranyl systems are anionic and therefore are associated with cations, justifying their 
description as mixed-metal cuboids in several cases. In fact, there are few examples of the formation of tetrahedral $\mathrm{M}_{4}$ clusters involving mixed ligands of any sort and these have arisen in examination of the retention of chirality in the conversion of $\mathrm{M}_{4} \mathrm{~A}_{6}$ species into $\mathrm{M}_{4} \mathrm{~B}_{6}$ without the isomeric distribution of intermediate species being of direct interest. ${ }^{67,65}$ In most known $\mathrm{M}_{4} \mathrm{~L}_{6}$ species, the metal ion centres are in a chiral environment and there is usually selectivity apparent in that all four centres in one cluster have the same chirality. ${ }^{31,64-66}$ This chiroselectivity within the cluster appears to extend to the ligand in that use of an enantiomerically pure ligand generates a single complex where all metal ion centres are of the same chirality. ${ }^{41}$ There are also examples where a chiral but inversion-labile ligand forms complexes where a given cluster has metal ion centres and ligands each of one enantiomeric form ${ }^{67}$ (although this aspect of the ligand structure is not explicitly noted in the original publication). In the present series of tetrahedral clusters, complexes 1 and $\mathbf{6}$ provide evidence for countercation dependence of the isomeric form, $\mathbf{1}$ being of the achiral $M_{4} A_{3} B_{3}$ form, and 6 a racemic mixture of the enantiomorphs $M_{4} A_{6}$ and $M_{4} B_{6}$.

Luminescence properties. The emission spectra of compounds 1, 3, 6 and 7 in the solid state were recorded at room temperature under excitation at a wavelength of $420 \mathrm{~nm}$, a value suitable for excitation of the uranyl chromophore, ${ }^{68}$ and they are shown in Figure 10; no sufficient amount of the other compounds in pure form was obtained for emission spectra recording. In all emission spectra, the vibronic progression corresponding to the $S_{11} \rightarrow S_{00}$ and $S_{10} \rightarrow S_{0 v}(v=0-4)$ electronic transitions ${ }^{69}$ is well apparent, with four or five peaks being intense and well-resolved. The positions of the most intense peaks in the spectra of $\mathbf{1 , 3}, \mathbf{6}$ and $\mathbf{7}$ are nearly identical, with differences that do not exceed $2 \mathrm{~nm}(484,504,527$ and $551 \mathrm{~nm}$ for 6$)$. These values are close to those reported for compounds 10, 11 and 13 (480-482, 501-503, 523-525 and 547-549 nm, the 
values for 12 being red-shifted by $\sim 3 \mathrm{~nm}),{ }^{27}$ and they are typical of uranyl complexes with three equatorial chelating carboxylate groups, ${ }^{10,54,55,70}$ being strongly blue-shifted with respect to the values associated with other environments, although exceptions do occur. ${ }^{71}$ The vibronic splitting energies for the $S_{10} \rightarrow S_{0 v}$ transitions average $833(20) \mathrm{cm}^{-1}$, a value in agreement with those usually measured for uranyl carboxylate complexes. ${ }^{54,69,71-73}$

\section{CONCLUSIONS}

The present and past structural studies of metal ion complexes of trans-1,2cyclohexanedicarboxylate show that it is a ligand which favours bridging over chelation through both carboxylate groups regardless of the nature of the metal ion. In its interactions with uranyl ion in a 1:1 ratio, this can lead to the formation of albeit buckled, sheet-like coordination polymer arrays (as in complex 9), even though the repulsive interactions between the adjacent carboxylates on a chair-form ring cause them to twist well away from coplanarity with one another. Where the ratio becomes 1:1.5 (uranyl:chdc), the uranium adopts a hexagonal bipyramidal coordination geometry involving three carboxylate chelate rings from separate ligand units, this resulting in the formation of a tetrahedral tetra-uranyl arrangement. The fact that uranyl ions do not fully balance the total anionic charge means that other cations must be present, and the interactions of these cations, either metallic or not, with the carboxylate groups possibly exert a structure-directing influence. When the racemic ligand is used, for example, particular isomers are favoured probably as a consequence of the coordination preferences of the particular countercations used. Thus, the conditions governing the formation of $\mathrm{M}_{4} \mathrm{~L}_{6}$ clusters where $\mathrm{M}$ is uranyl and $\mathrm{L}$ is dianionic are clearly rather different to those where $\mathrm{M}$ is a transition or main group metal ion able to adopt a chiral form. Nonetheless, there are common features such as the capacity of the ligand to enforce 
a particular disposition of the donor sites compatible with a particular cluster geometry, as we have shown elsewhere that long chain dicarboxylates can be sufficiently flexible to form binuclear, triple-stranded helicate species where formally a $\left[\mathrm{UO}_{2}\left(\mathrm{O}_{2} \mathrm{C}\left(\mathrm{CH}_{2}\right)_{n} \mathrm{CO}_{2}\right)_{3}\right]^{4-}(n=9,12)$ species simply envelops a second uranyl ion. ${ }^{15}$ The conformational restrictions of the substituted cyclohexane ring in $(R-) \operatorname{chdc}^{2-}$ must therefore play a role.

The eight complexes described herein, together with those formerly reported, show the different association modes of the robust tetrahedral uranyl cage anion, whatever its isomeric form, with different counterions. The species formed range from isolated tetrahedral clusters in the homometallic complex 1 (that shows that additional carboxylate-bound metal ions are unnecessary for the cage formation), to $2 \mathrm{D}$ and $3 \mathrm{D}$ assemblies in which tetrahedra are bridged by metal counterions, and to incorporation of the latter into heterometallic cuboidal clusters, either isolated or bridged by water molecules to form higher dimensionality assemblies. Apart from the scarcity of such closed cages in uranyl chemistry, the countercation dependence and the variety of the assemblies generated are notable. Metal-organic frameworks incorporating metal clusters as network nodes and their properties have been recently reviewed. ${ }^{40}$ The peculiarity of the present complexes, as a particular subgroup of these species, is that the dicarboxylate ligands are part of the cluster motif and do not serve to directly connect different metal clusters through divergent coordination sites, the links being provided instead by countercations and water ligands, with the consequence that no significant porosity can be expected.

\section{ASSOCIATED CONTENT}

\section{Supporting Information}

The Supporting Information is available free of charge on the ACS Publications website at DOI:. X-ray crystallographic information. (CIF) 


\section{AUTHOR INFORMATION}

\section{Corresponding Authors}

*E-mail: pierre.thuery@cea.fr. (P.T.)

*E-mail: harrowfield@unistra.fr. (J.H.)

\section{Notes}

The authors declare no competing financial interest.

\section{REFERENCES}

1. Poojary, D. M.; Cabeza, A.; Aranda, M. A. G.; Bruque, S.; Clearfield, A. Structure Determination of a Complex Tubular Uranyl Phenylphosphonate, $\left(\mathrm{UO}_{2}\right)_{3}\left(\mathrm{HO}_{3} \mathrm{PC}_{6} \mathrm{H}_{5}\right)_{2}\left(\mathrm{O}_{3} \mathrm{PC}_{6} \mathrm{H}_{5}\right)_{2} \cdot \mathrm{H}_{2} \mathrm{O}$, from Conventional X-ray Powder Diffraction Data. Inorg. Chem. 1996, 35, 1468-1473.

2. Grohol, D.; Clearfield, A. Alkali-Ion-Catalyzed Transformation of Two Linear Uranyl Phosphonates into a Tubular One. J. Am. Chem. Soc. 1997, 119, 9301-9302.

3. Krivovichev, S. V.; Kahlenberg, V.; Tananaev, I. G.; Kaindl, R.; Mersdorf, E.; Myasoedov, B. F. Highly Porous Uranyl Selenate Nanotubules. J. Am. Chem. Soc. 2005, 127, 1072-1073.

4. Krivovichev, S. V.; Kahlenberg, V.; Kaindl, R.; Mersdorf, E.; Tananaev, I. G.; Myasoedov, B. F. Nanoscale Tubules in Uranyl Selenates. J. Angew. Chem. Int. Ed. 2005, 44, 1134-1136.

5. Adelani, P. O.; Albrecht-Schmitt, T. E. Metal-Controlled Assembly of Uranyl Diphosphonates toward the Design of Functional Uranyl Nanotubules. Inorg. Chem. 2011, 50, 12184-12191.

6. Adelani, P. O.; Cook, N. D.; Babo, J. M.; Burns, P. C. Incorporation of $\mathrm{Cu}^{2+}$ Ions into Nanotubular Uranyl Diphosphonates. Inorg. Chem. 2014, 53, 4169-4176. 
7. Mihalcea, I.; Henry, N.; Loiseau T. Revisiting the Uranyl-Phthalate System: Isolation and Crystal Structures of Two Types of Uranyl-Organic Frameworks (UOF). Cryst. Growth Des. 2011, 11, $1940-1947$.

8. Unruh, D. K.; Gojdas, K.; Libo, A.; Forbes, T. Z. Development of Metal-Organic Nanotubes Exhibiting Low-Temperature, Reversible Exchange of Confined "Ice Channels". J. Am. Chem. Soc. 2013, 135, 7398-7401.

9. Thuéry, P. A Highly Adjustable Coordination System: Nanotubular and Molecular Cage Species in Uranyl Ion Complexes with Kemp's Triacid. Cryst. Growth Des. 2014, 14, 901-904.

10. Thuéry, P.; Harrowfield, J. Uranyl Ion Complexes with all-cis-1,3,5-Cyclohexanetricarboxylate: Unexpected Framework and Nanotubular Assemblies. Cryst. Growth Des. 2014, 14, 4214-4225.

11. Thuéry, P.; Harrowfield, J. Variations on the Honeycomb Topology: from Triangular- and SquareGrooved Networks to Tubular Assemblies in Uranyl Tricarballylate Complexes. Cryst. Growth Des., DOI: 10.1021/acs.cgd.7b00126.

12. Thuéry, P.; Nierlich, M.; Baldwin, B. W.; Komatsuzaki, N.; Hirose, T. A Metal-Organic Molecular Box Obtained from Self-Assembling around Uranyl Ions. J. Chem. Soc., Dalton Trans., 1999, 1047-1048.

13. Thuéry, P. A Nanosized Uranyl Camphorate Cage and its Use as a Building Unit in a MetalOrganic Framework. Cryst. Growth Des. 2009, 9, 4592-4594.

14. Thuéry, P. Increasing Complexity in the Uranyl Ion-Kemp's Triacid System: From One- and Two-Dimensional Polymers to Uranyl-Copper(II) Dodeca- and Hexadecanuclear Species. Cryst. Growth Des. 2014, 14, 2665-2676.

15. Thuéry, P.; Harrowfield, J. A New Form of Triple-Stranded Helicate Found in Uranyl Complexes of Aliphatic $\alpha, \omega$-Dicarboxylates. Inorg. Chem. 2015, 54, 10539-10541. 
16. Pasquale, S.; Sattin, S.; Escudero-Adán, E. C.; Martínez-Belmonte, M.; de Mendoza, J. Giant Regular Polyhedra from Calixarene Carboxylates and Uranyl. Nature Commun. 2012, 3, 785-791. 17. Qiu, J.; Burns, P. C. Clusters of Actinides with Oxide, Peroxide, or Hydroxide Bridges. Chem. Rev. 2013, 113, 1097-1120.

18. Ling, J.; Hobbs, F.; Prendergast, S.; Adelani, P. O.; Babo, J. M.; Qiu, J.; Weng, Z.; Burns, P. C. Hybrid Uranium-Transition-Metal Oxide Cage Clusters. Inorg. Chem. 2014, 53, 12877-12884.

19. Sigmon, G. E.; Szymanowski, J. E. S.; Carter, K. P.; Cahill, C. L.; Burns, P. C. Hybrid Lanthanide-Actinide Peroxide Cage Clusters. Inorg. Chem. 2016, 55, 2682-2684.

20. Dembowski, M.; Olds, T. A.; Pellegrini, K. L.; Hoffmann, C.; Wang, X.; Hickam, S.; He, J.; Oliver, A. G.; Burns, P. C. Solution ${ }^{31}$ P NMR Study of the Acid-Catalyzed Formation of a Highly Charged $\left\{\mathrm{U}_{24} \mathrm{Pp}_{12}\right\}$ Nanocluster, $\left[\left(\mathrm{UO}_{2}\right)_{24}\left(\mathrm{O}_{2}\right)_{24}\left(\mathrm{P}_{2} \mathrm{O}_{7}\right)_{12}\right]^{48-}$, and Its Structural Characterization in the Solid State Using Single-Crystal Neutron Diffraction. J. Am. Chem. Soc. 2016, 138, $8547-8553$.

21. Hickam, S.; Burns, P. C. Oxo Clusters of $5 f$ Elements. Struct. Bonding (Berlin, Ger.) 2017, 173, $121-154$.

22. Thuéry, P.; Villiers, C.; Jaud, J.; Ephritikhine, M.; Masci, B. Uranyl-Based Metallamacrocycles: Tri- and Tetranuclear Complexes with $(2 R, 3 R, 4 S, 5 S)$-Tetrahydrofurantetracarboxylic Acid. J. Am. Chem. Soc. 2004, 126, 6838-6839.

23. Charushnikova, I. A.; Grigor'ev, M. S.; Krot, N. N. Synthesis and Crystal Structure of New U(VI) and $\mathrm{Np}(\mathrm{VI})$ Benzoates, $\mathrm{K}_{11}\left(\mathrm{AnO}_{2}\right)_{23}\left(\mathrm{OOCC}_{6} \mathrm{H}_{5}\right)_{57}\left(\mathrm{H}_{2} \mathrm{O}\right)_{18+x}$. Radiochemistry 2010, 52, $138-144$.

24. Andrews, M. B.; Cahill, C. L. Uranyl Bearing Hybrid Materials: Synthesis, Speciation, and SolidState Structures. Chem. Rev. 2013, 113, 1121-1136.

25. Loiseau, T.; Mihalcea, I.; Henry, N.; Volkringer, C. The Crystal Chemistry of Uranium Carboxylates. Coord. Chem. Rev. 2014, 266-267, 69-109. 
26. Su, J.; Chen, J. S. MOFs of Uranium and the Actinides. Struct. Bond. 2015, 163, 265-296.

27. Thuéry, P.; Harrowfield, J. Coordination Polymers and Cage-Containing Frameworks in Uranyl Ion Complexes with rac- and (1R,2R)-trans-1,2-Cyclohexanedicarboxylates: Consequences of Chirality. Inorg. Chem. 2017, 56, 1455-1469.

28. Salmon, L.; Thuéry, P.; Ephritikhine, M. Crystal Structure of the First Octanuclear Uranium(IV) Complex with Compartmental Schiff Base Ligands. Polyhedron 2004, 23, 623-627.

29. Salmon, L.; Thuéry, P.; Ephritikhine, M. Polynuclear Uranium(IV) Compounds with ( $\mu_{3}$-oxo) $\mathrm{U}_{3}$ or ( $\mu_{4}$-oxo $) \mathrm{U}_{4}$ Cores and Compartmental Schiff Base Ligands. Polyhedron 2006, 25, 1537-1542.

30. Baxter, P. W. N. Metal Ion Directed Assembly of Complex Molecular Architectures and Nanostructures. In Comprehensive Supramolecular Chemistry, Eds. Atwood, J. L.; Davies, J. E. D.; Macnicol, D. D.; Vögtle, F., Vol. 9, Ch. 5, pp. 165-211 (Vol. Eds. Sauvage, J.-P.; Hosseini, M. W.), Elsevier Science, Oxford, UK, 1996.

31. Caulder, D. L.; Raymond, K. N. Supermolecules by Design. Acc. Chem. Res. 1999, 32, 975-982.

32. Saalfrank, R. W.; Demleitner, B.; Glaser, H.; Maid, H.; Bathelt, D.; Hampel, F.; Bauer, W.; Teichert, M. Enantiomerisation of Tetrahedral Homochiral [ $\left.\mathrm{M}_{4} \mathrm{~L}_{6}\right]$ Clusters: Synchronised Four Bailar Twists and Six Atropenantiomerisation Processes Monitored by Temperature-Dependent Dynamic ${ }^{1}$ H NMR Spectroscopy. Chem. Eur. J. 2002, 8, 2679-2683.

33. Seidel, S. R.; Stang, P. J. High-Symmetry Coordination Cages via Self-Assembly. Acc. Chem. Res. 2002, 35, 972-983.

34. Clegg, J. K.; Lindoy, L. F.; Moubaraki, B.; Murray, K. S.; McMurtrie, J. C. Triangles and Tetrahedra: Metal-Directed Self-Assembly of Metallosupramolecular Structures Incorporating Bis- $\beta$-diketonato Ligands. Dalton Trans. 2004, 33, 2417-2423. 
35. Fiedler, D.; Leung, D. H.; Bergman, R. G.; Raymond, K. N. Selective Molecular Catalysis in Nanoscale Reaction Vessels. Acc. Chem. Res. 2005, 38, 351-360.

36. Dalgarno, S. J.; Power, N. P.; Atwood, J. L. Metallosupramolecular Capsules. Coord. Chem. Rev. 2008, 252, 825-841.

37. Young, W. J.; Hay, B. P. Structural Design Principles for Self Assembled Coordination Polygons and Polyhedra. Chem. Commun. 2013, 49, 1354-1379.

38. Ronson, T. K.; Zarra, S.; Black, S. P. Nitschke, J. R. Metal-Organic Container Molecules through Subcomponent Self Assembly. Chem. Commun. 2013, 49, 2476-2490.

39. Zarra, S.; Wood, D. M.; Roberts, D. A.; Nitschke, J. R. Molecular Containers in Complex Chemical Systems. Chem. Soc. Rev. 2015, 44, 419-432.

40. Qin, L.; Zheng, H. G. Structures and Applications of Metal-Organic Frameworks Featuring Metal Clusters. CrystEngComm 2017, 19, 745-757.

41. Argent, S. P.; Riis-Johannessen, T.; Jeffery, J. C.; Harding, L. P.; Ward; M. D. Diastereoselective Formation and Optical Activity of an $\mathrm{M}_{4} \mathrm{~L}_{6}$ Cage Complex. Chem. Commun. 2005, 4647-4649.

42. Meng, W.; Clegg, J. K.; Thoburn, S. D.; Nitschke, J. R. Controlling the Transmission of Stereochemical Information through Space in Terphenyl-Edged $\mathrm{M}_{4} \mathrm{~L}_{6}$ Cages. J. Am. Chem Soc. 2011, 133, 13652-13660.

43. Meng, W.; Ronson, T. K.; Nitschke, J.R. Symmetry-Breaking in Self-Assembled $\mathrm{M}_{4} \mathrm{~L}_{6}$ Cage Complexes. Proc. Natl. Acad. Sci. USA 2013, 110, 10531-10535.

44. Ronson, T. K.; League, A. B.; Gagliardi, L.; Cramer, C. J.; Nitschke, J. R. Pyrene-Edged Fe ${ }_{4}^{\mathrm{II}} \mathrm{L}_{6}$ Cages Adaptively Reconfigure During Guest Binding. J. Am. Chem Soc. 2014, 136, 15615-15624. 45. Kimura, K.; Watanabe, Y.; Suda, T.; Senda, H.; Hosoi, S.; Ohta, T.; Kunimoto, K. K. Crystal Structure of $(1 R, 2 R)$-trans-1,2-Cyclohexanedicarboxylic Acid-( $R)$-1-Phenylethylamine Salt. Anal. Sci. 1999, 15, 609-610. 
46. Hooft, R. W. W. COLLECT, Nonius BV: Delft, The Netherlands, 1998.

47. Otwinowski, Z.; Minor, W. Processing of X-Ray Diffraction Data Collected in Oscillation Mode. Methods Enzymol. 1997, 276, 307-326.

48. Sheldrick, G. M. A Short History of SHELX. Acta Crystallogr., Section A 2008, 64, 112-122.

49. Sheldrick, G. M. SHELXT - Integrated Space-Group and Crystal-Structure Determination. Acta Crystallogr., Sect. A 2015, 71, 3-8.

50. Sheldrick, G. M. Crystal Structure Refinement with SHELXL. Acta Crystallogr., Sect. C 2015, $71,3-8$.

51. Spek, A. L. Structure Validation in Chemical Crystallography. Acta Crystallogr., Sect. D 2009, $65,148-155$.

52. Farrugia, L. J. WinGX and ORTEP for Windows: an Update. J. Appl. Crystallogr. 2012, 45, 849854.

53. Momma, K.; Izumi, F. VESTA: a Three-Dimensional Visualization System for Electronic and Structural Analysis. J. Appl. Crystallogr. 2008, 41, 653-658.

54. Thuéry, P.; Rivière, E.; Harrowfield, J. Counterion-Induced Variations in the Dimensionality and Topology of Uranyl Pimelate Complexes. Cryst. Growth Des. 2016, 16, 2826-2835.

55. Thuéry, P.; Harrowfield, J. Modulation of the Structure and Properties of Uranyl Ion Coordination Polymers Derived from 1,3,5-Benzenetriacetate by Incorporation of $\mathrm{Ag}(\mathrm{I})$ or $\mathrm{Pb}(\mathrm{II})$. Inorg. Chem. 2016, 55, 6799-6816 and references therein.

56. Whiteside, A.; Xantheas, S. S.; Gutowski, M. Is Electronegativity a Useful Descriptor for the Pseudo-Alkali Metal NH 4 ? Chem. Eur. J. 2011, 17, 13197-13205.

57. Groom, C. R.; Bruno, I. J.; Lightfoot, M. P.; Ward, S. C. The Cambridge Structural Database. Acta Crystallogr., Sect. B 2016, 72, 171-179. 
58. Thuéry, P.; Masci, B. A Bis(p-tert-butyloctahomotetraoxacalix[8]arene) Capsule with $\left[\left(\mathrm{UO}_{2}\right)_{2}(\mathrm{OH})_{2}\right]$ Links and a Disordered $\left[\mathrm{Rb}_{4}\left(\mathrm{H}_{2} \mathrm{O}\right)_{4}\right]$ Inner Core. Supramol. Chem. 2004, 16, 8186.

59. Thuéry, P.; Masci, B. Synthesis and Crystal Structure of 1:2 Mixed Uranyl/Alkali Metal Ions (Li ${ }^{+}$, $\mathrm{Na}^{+}, \mathrm{K}^{+}, \mathrm{Cs}^{+}$) Complexes of p-tert-Butyltetrahomodioxacalix[4]arene. Dalton Trans. 2003, 24112417.

60. Thuéry, P.; Masci, B. Hydrothermal Synthesis of Uranyl-Organic Frameworks with Pyrazine-2,3dicarboxylate Linkers. CrystEngComm 2008, 10, 1082-1087.

61. Adelani, P. O.; Oliver, A. G.; Albrecht-Schmitt, T. E. Layered and Three-Dimensional Framework Cesium and Barium Uranyl Carboxyphenylphosphonates. Cryst. Growth Des. 2011, 11, 30723080.

62. Shannon, R. D. Revised Effective Ionic Radii and Systematic Studies of Interatomic Distances in Halides and Chalcogenides. Acta Crystallogr., Sect. A 1976, 32, 751-767.

63. Harrowfield, J.; Thuéry, P. Charge Localisation in Heavy Alkali Metal Ion Complexes of 4,4'Biphenyldicarboxylate. Aust. J. Chem. 2016, 69, 505-511.

64. Ziegler, M.; Davis, A. V.; Johnson, D. W.; Raymond, K. N. Supramolecular Chirality: a Reporter of Structural Memory. Angew. Chem. Int. Ed. 2003, 42, 665-668.

65. Ousaka, N.; Clegg, J. K.; Nitschke, J. R. Nonlinear Enhancement of Chiroptical Response through Subcomponent Substitution in $\mathrm{M}_{4} \mathrm{~L}_{6}$ Cages. Angew. Chem. Int. Ed. 2012, 51, 1464-1468.

66. Caulder, D. L.; Brückner, C.; Powers, R. E.; König, S.; Parac, T. N.; Leary, J. A.; Raymond, K. N. Design, Formation and Properties of Tetrahedral $\mathrm{M}_{4} \mathrm{~L}_{4}$ and $\mathrm{M}_{4} \mathrm{~L}_{6}$ Supramolecular Clusters. $J$. Am. Chem. Soc. 2001, 123, 8923-8938.

67. Mal, P.; Schultz, D.; Beyeh, K.; Rissanen, K.; Nitschke, J. R. An Unlockable-Relockable Iron Cage by Subcomponent Self-Assembly. Angew. Chem. Int. Ed. 2008, 47, 8297-8301. 
68. Knope, K. E.; de Lill, D. T.; Rowland, C. E.; Cantos, P. M.; de Bettencourt-Dias, A.; Cahill, C. L. Uranyl Sensitization of Samarium(III) Luminescence in a Two-Dimensional Coordination Polymer. Inorg. Chem. 2012, 51, 201-206.

69. Brachmann, A.; Geipel, G.; Bernhard, G.; Nitsche, H. Study of Uranyl(VI) Malonate Complexation by Time Resolved Laser-Induced Fluorescence Spectroscopy (TRLFS). Radiochim. Acta 2002, 90, 147-153.

70. Thuéry, P.; Harrowfield, J. Uranyl Ion Complexes with Long-Chain Aliphatic $\alpha$, $\omega$-Dicarboxylates and 3d-Block Metal Counterions. Inorg. Chem. 2016, 55, 2133-2145.

71. Thuéry, P.; Harrowfield, J. Counter-Ion Control of Structure in Uranyl Ion Complexes with 2,5Thiophenedicarboxylate. CrystEngComm 2016, 18, 1550-1562.

72. Surbella, R. G., III; Andrews, M. B.; Cahill, C. L. Self-assembly of $\left[\mathrm{UO}_{2} \mathrm{X}_{4}\right]^{2-}(\mathrm{X}=\mathrm{Cl}, \mathrm{Br})$ Dianions with $\gamma$ Substituted Pyridinium Cations: Structural Systematics and Fluorescence Properties. J. Solid State Chem. 2016, 236, 257-271.

73. Martin, N. P.; Falaise, C.; Volkringer, C.; Henry, N.; Farger, P.; Falk, C.; Delahaye, E.; Rabu, P.; Loiseau, T. Hydrothermal Crystallization of Uranyl Coordination Polymers Involving an Imidazolium Dicarboxylate Ligand: Effect of $\mathrm{pH}$ on the Nuclearity of Uranyl-Centered Subunits. Inorg. Chem. 2016, 55, 8697-8705. 
Table 1. Crystal Data and Structure Refinement Details

\begin{tabular}{|c|c|c|c|c|c|c|c|c|}
\hline & 1 & 2 & 3 & 4 & 5 & 6 & 7 & 8 \\
\hline chemical formula & $\mathrm{C}_{48} \mathrm{H}_{76} \mathrm{~N}_{4} \mathrm{O}_{32} \mathrm{U}_{4}$ & $\mathrm{C}_{48} \mathrm{H}_{72} \mathrm{~K}_{4} \mathrm{O}_{38} \mathrm{U}_{4}$ & $\mathrm{C}_{50} \mathrm{H}_{71.5} \mathrm{NO}_{33.75} \mathrm{Rb}_{3} \mathrm{U}_{4}$ & $\mathrm{C}_{53} \mathrm{H}_{77} \mathrm{NO}_{37} \mathrm{Rb}_{4} \mathrm{U}_{4}$ & $\mathrm{C}_{48} \mathrm{H}_{66} \mathrm{O}_{35} \mathrm{Rb}_{4} \mathrm{U}_{4}$ & $\mathrm{C}_{48} \mathrm{H}_{68} \mathrm{Cs}_{4} \mathrm{O}_{36} \mathrm{U}_{4}$ & $\mathrm{C}_{48} \mathrm{H}_{74} \mathrm{Cs}_{4} \mathrm{O}_{39} \mathrm{U}_{4}$ & $\mathrm{C}_{48} \mathrm{H}_{76} \mathrm{Ba}_{2} \mathrm{O}_{40} \mathrm{U}_{4}$ \\
\hline$M\left(\mathrm{~g} \mathrm{~mol}^{-1}\right)$ & 2173.24 & 2365.57 & 2435.11 & 2614.15 & 2497.00 & 2704.78 & 2758.83 & 2519.88 \\
\hline cryst syst & tetragonal & tetragonal & monoclinic & monoclinic & trigonal & cubic & orthorhombic & tetragonal \\
\hline space group & $I 4_{1} / a$ & $I 4{ }_{12} 2$ & $C 2$ & $P 2_{1}$ & $R 32$ & $P a-3$ & $C 222_{1}$ & $P 4_{3} 2_{12}$ \\
\hline$a(\AA)$ & $18.5632(6)$ & $17.1637(8)$ & $26.1974(7)$ & $16.1326(2)$ & $18.9236(8)$ & $24.3752(3)$ & $15.2081(6)$ & $17.1157(5)$ \\
\hline$b(\AA)$ & $18.5632(6)$ & $17.1637(8)$ & $19.1654(5)$ & $25.4852(7)$ & $18.9236(8)$ & $24.3752(3)$ & $24.2485(8)$ & $17.1157(5)$ \\
\hline$c(\AA)$ & $18.7065(10)$ & $22.4606(15)$ & $16.9355(5)$ & $19.1105(6)$ & $37.4103(18)$ & $24.3752(3)$ & $21.3024(6)$ & $23.7866(10)$ \\
\hline$\alpha(\mathrm{deg})$ & 90 & 90 & 90 & 90 & 90 & 90 & 90 & 90 \\
\hline$\beta(\mathrm{deg})$ & 90 & 90 & $116.032(3)$ & $90.059(2)$ & 90 & 90 & 90 & 90 \\
\hline$\gamma(\mathrm{deg})$ & 90 & 90 & 90 & 90 & 120 & 90 & 90 & 90 \\
\hline$V\left(\AA^{3}\right)$ & $6446.1(5)$ & $6616.7(8)$ & $7640.4(4)$ & $7857.1(3)$ & $11601.9(13)$ & $14482.5(5)$ & $7855.8(5)$ & $6968.2(5)$ \\
\hline$Z$ & 4 & 4 & 4 & 4 & 6 & 8 & 4 & 4 \\
\hline$D_{\text {calcd }}\left(\mathrm{g} \mathrm{cm}^{-3}\right)$ & 2.239 & 2.375 & 2.117 & 2.210 & 2.144 & 2.481 & 2.333 & 2.402 \\
\hline$\mu(\operatorname{Mo~K} \alpha)\left(\mathrm{mm}^{-1}\right)$ & 10.110 & 10.110 & 10.431 & 10.766 & 10.929 & 10.986 & 10.132 & 10.470 \\
\hline$F(000)$ & 4064 & 4432 & 4510 & 4856 & 6900 & 9856 & 5048 & 4656 \\
\hline reflns collcd & 101736 & 59479 & 100381 & 182063 & 67538 & 423002 & 96772 & 195761 \\
\hline indep reflns & 3060 & 3143 & 14339 & 28783 & 3732 & 4584 & 7476 & 6483 \\
\hline obsd reflns $[I>2 \sigma(I)]$ & 2870 & 2575 & 10693 & 25085 & 2321 & 3727 & 7001 & 5857 \\
\hline$R_{\text {int }}$ & 0.029 & 0.059 & 0.041 & 0.046 & 0.061 & 0.016 & 0.025 & 0.041 \\
\hline params refined & 200 & 218 & 861 & 1888 & 276 & 293 & 434 & 426 \\
\hline$R_{1}$ & 0.033 & 0.057 & 0.054 & 0.041 & 0.059 & 0.046 & 0.031 & 0.041 \\
\hline$w R_{2}$ & 0.081 & 0.141 & 0.139 & 0.099 & 0.171 & 0.119 & 0.082 & 0.095 \\
\hline$S$ & 1.149 & 1.127 & 1.021 & 1.030 & 0.960 & 1.014 & 1.086 & 1.138 \\
\hline$\Delta \rho_{\min }\left(\mathrm{e} \AA^{-3}\right)$ & -0.75 & -1.07 & -0.72 & -2.24 & -1.04 & -2.10 & -0.77 & -0.92 \\
\hline$\Delta \rho_{\max }\left(\mathrm{e} \AA^{-3}\right)$ & 2.64 & 1.77 & 1.60 & 1.33 & 1.10 & 2.62 & 1.93 & 2.28 \\
\hline Flack parameter & & $0.08(3)$ & $0.034(15)$ & $0.021(8)$ & $0.05(3)$ & & $0.008(8)$ & $0.005(4)$ \\
\hline
\end{tabular}




\section{Figure Captions}

Scheme 1. Possible isomers of a tetrahedral metallocluster with mixed bridging of the tetrahedron edges by symmetrical ditopic but achiral ligands A (red) and B (blue).

Figure 1. Top left: View of compound 1. Displacement ellipsoids are drawn at the $30 \%$ probability level. Hydrogen bonds are shown as dashed lines. Symmetry codes: $i=y+1 / 4,3 / 4$ $-x, 7 / 4-z ; \mathrm{j}=3 / 4-y, x-1 / 4,7 / 4-z ; \mathrm{k}=1-x, 1 / 2-y, z$. Top right: Similar view showing uranium coordination polyhedra. Bottom: View of the packing. Hydrogen atoms are omitted in all views, except for those of the counterions.

Figure 2. Top: View of compound 2. Displacement ellipsoids are drawn at the $20 \%$ probability level. Symmetry codes: $\mathrm{i}=3 / 2-y, 3 / 2-x, 3 / 2-z ; \mathrm{j}=y-1 / 2, x+1 / 2,3 / 2-z ; \mathrm{k}=1-x, 2-y$, $z ; 1=1 / 2-x, y, 7 / 4-z ; \mathrm{m}=1-y, x+1 / 2, z+1 / 4 ; \mathrm{n}=y-1,3 / 2-x, z+1 / 4$. Bottom: View of the packing with uranium polyhedra colored yellow and potassium atoms shown as green spheres. Hydrogen atoms are omitted in all views.

Figure 3. Top left: View of compound 3. Displacement ellipsoids are drawn at the $30 \%$ probability level. Oxo bonding to rubidium is omitted for clarity, as well as counterions and carbon-bound hydrogen atoms. The hydrogen bond is shown as a dashed line. Symmetry codes: $\mathrm{i}=1 / 2-x, y-1 / 2,1-z ; \mathrm{j}=1 / 2-x, y+1 / 2,1-z ; \mathrm{k}=1-x, y, 2-z$. Top right: View of the incomplete cuboidal cage with uranium coordination polyhedra colored yellow and rubidium atoms shown as green spheres. Bottom left: View of the 2D assembly. Bottom right: View of the packing with counterions and hydrogen atoms omitted. 
Figure 4. Arrangement of the proximal alkali or alkaline-earth metal cations around the tetrahedral uranyl motif in complexes $\mathbf{2}$ and $\mathbf{8}$, and complete or incomplete cuboidal cages in 3-7. Except for the $\mathrm{U}=\mathrm{O}$ bonds, lines are guides for the eye.

Figure 5. Top left: View of one of the two independent cages in compound 4. Displacement ellipsoids are drawn at the $30 \%$ probability level. Oxo bonding to rubidium is omitted for clarity. Symmetry codes: $\mathrm{i}=2-x, y-1 / 2,1-z ; \mathrm{j}=1-x, y-1 / 2,1-z$. Top right: View showing the bridging of two incomplete cuboidal cages by rubidium atoms. Bottom: View of the 3D framework with the uranium coordination polyhedra colored yellow and rubidium atoms shown as green spheres. Solvent molecules and hydrogen atoms are omitted in all views.

Figure 6. Top left: View of compound 5. Displacement ellipsoids are drawn at the $10 \%$ probability level. Oxo bonding to rubidium is omitted for clarity. Symmetry codes: $\mathrm{i}=1-y, x$ $-y, z ; \mathrm{j}=y-x+1,1-x, z ; \mathrm{k}=x-y+2 / 3,4 / 3-y, 4 / 3-z$. Top right: View of the $2 \mathrm{D}$ assembly with uranium coordination polyhedra colored yellow and rubidium atoms shown as green spheres. Bottom: View of the packing with layers viewed edge-on. Solvent molecules and hydrogen atoms are omitted in all views.

Figure 7. Top left: View of compound 6. Displacement ellipsoids are drawn at the $30 \%$ probability level. Oxo bonding to cesium is omitted for clarity, as well as solvent molecules and carbon-bound hydrogen atoms. Symmetry codes: $\mathrm{i}=z, x, y ; \mathrm{j}=y, z, x$. Top right: View of the molecular cuboidal cage with uranium coordination polyhedra colored yellow and cesium atoms shown as blue spheres. Bottom: View of the packing with solvent molecules and hydrogen atoms omitted. 
Figure 8. Top: View of compound 7. Displacement ellipsoids are drawn at the 50\% probability level. Oxo bonding to cesium is omitted for clarity, as well as solvent molecules and carbonbound hydrogen atoms. Symmetry codes: $\mathrm{i}=1-x, y, 1 / 2-z ; \mathrm{j}=x, 1-y,-z ; \mathrm{k}=1-x, 1-y, z$ $+1 / 2$. Middle: View of the $1 \mathrm{D}$ assembly with uranium coordination polyhedra colored yellow and cesium atoms shown as blue spheres. Bottom: View of the packing with chains viewed endon, and solvent molecules and hydrogen atoms omitted.

Figure 9. Top: View of compound 8. Displacement ellipsoids are drawn at the $30 \%$ probability level. Carbon-bound hydrogen atoms are omitted and hydrogen bonds are shown as dashed lines. Symmetry codes: $\mathrm{i}=1-y, 1-x, 3 / 2-z ; \mathrm{j}=1 / 2-x, y-1 / 2,7 / 4-z ; \mathrm{k}=1 / 2-x, y+1 / 2$, $7 / 4-z ; 1=1 / 2-y, x+1 / 2, z-1 / 4$. Bottom: View of the $3 \mathrm{D}$ framework with uranium coordination polyhedra colored yellow, barium atoms shown as blue spheres and hydrogen atoms omitted.

Figure 10. Emission spectra of compounds 1, 3, 6 and 7. The excitation wavelength was 420 nm. 
Scheme 1
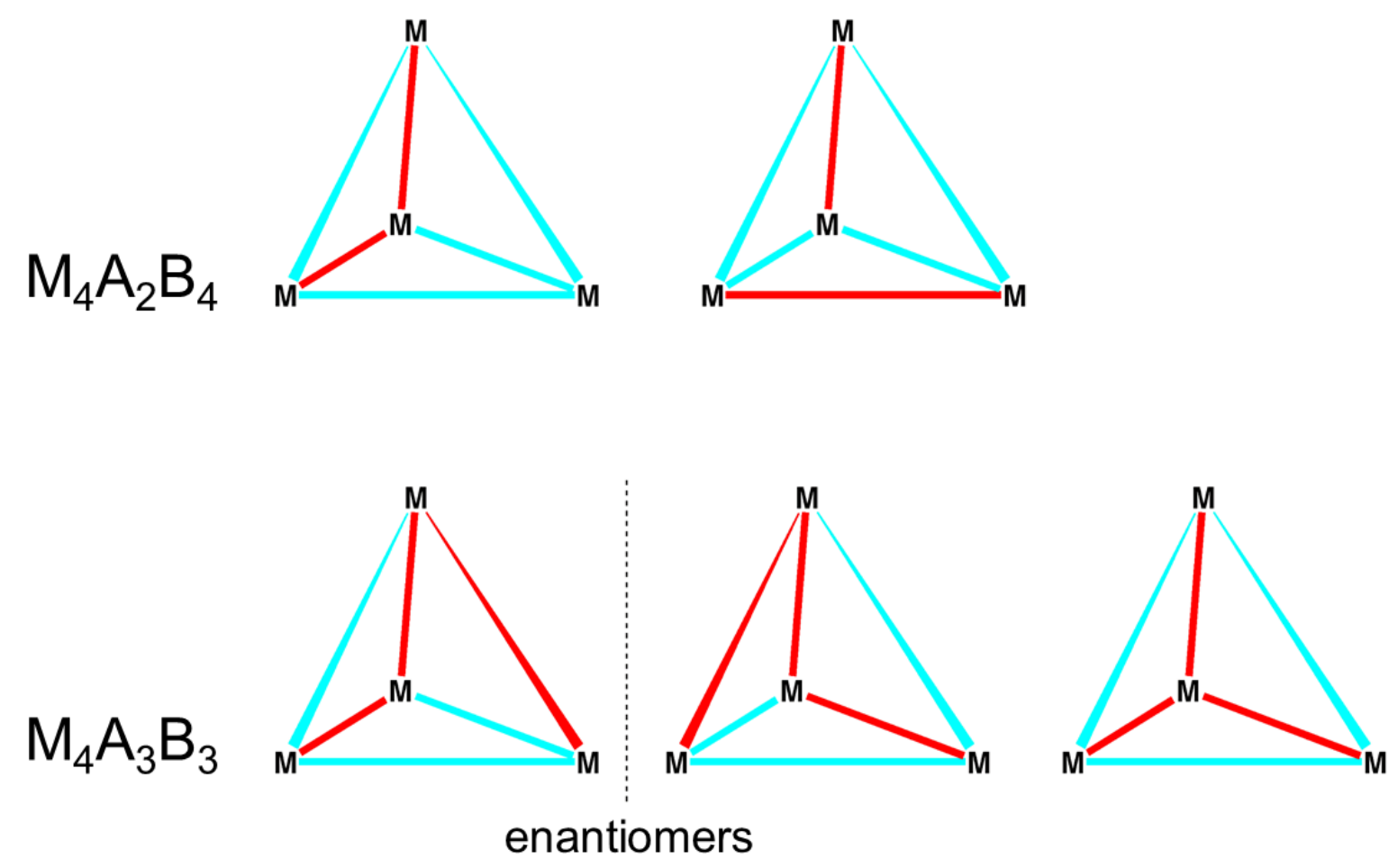

enantiomers 
Figure 1

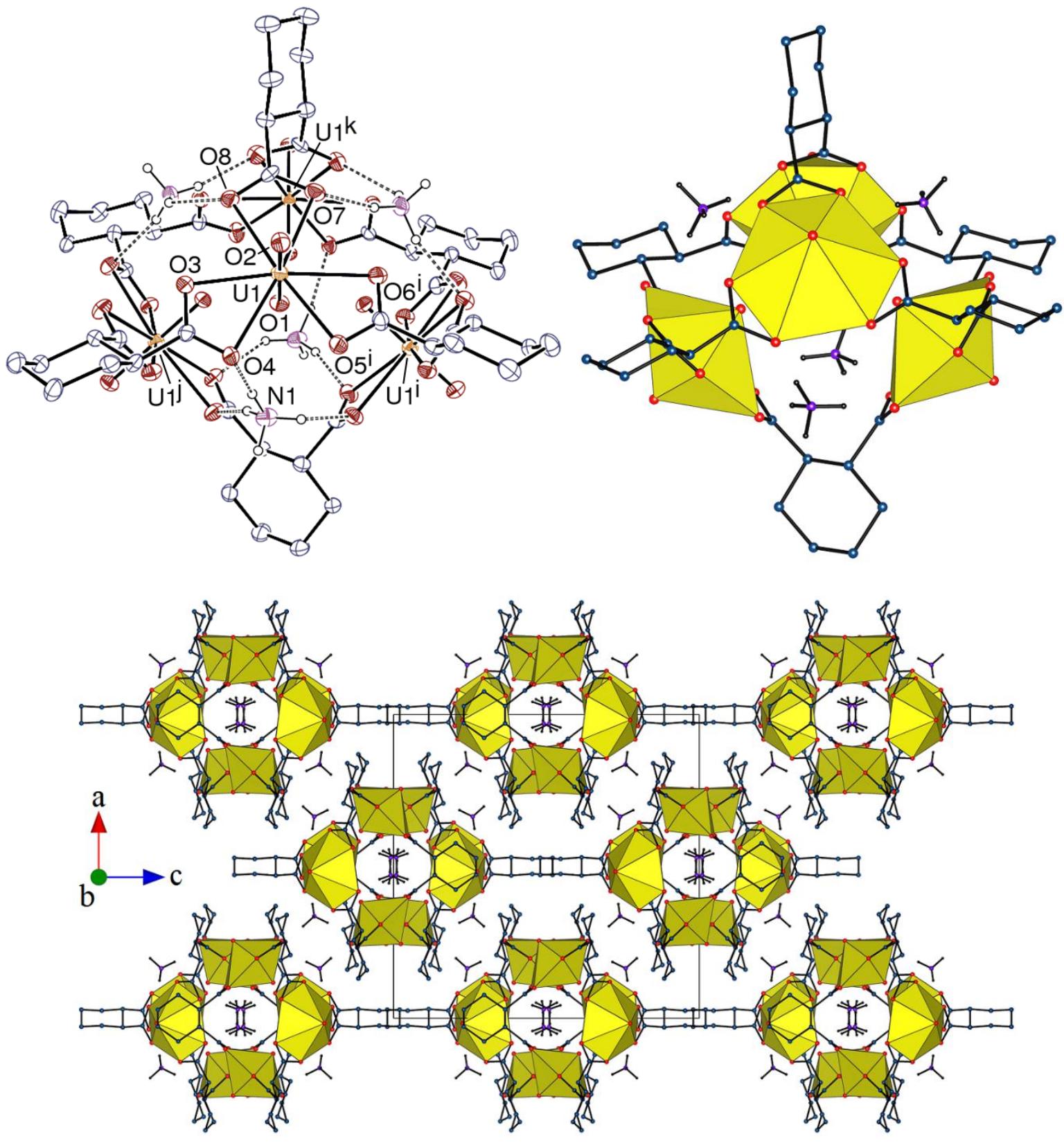


Figure 2
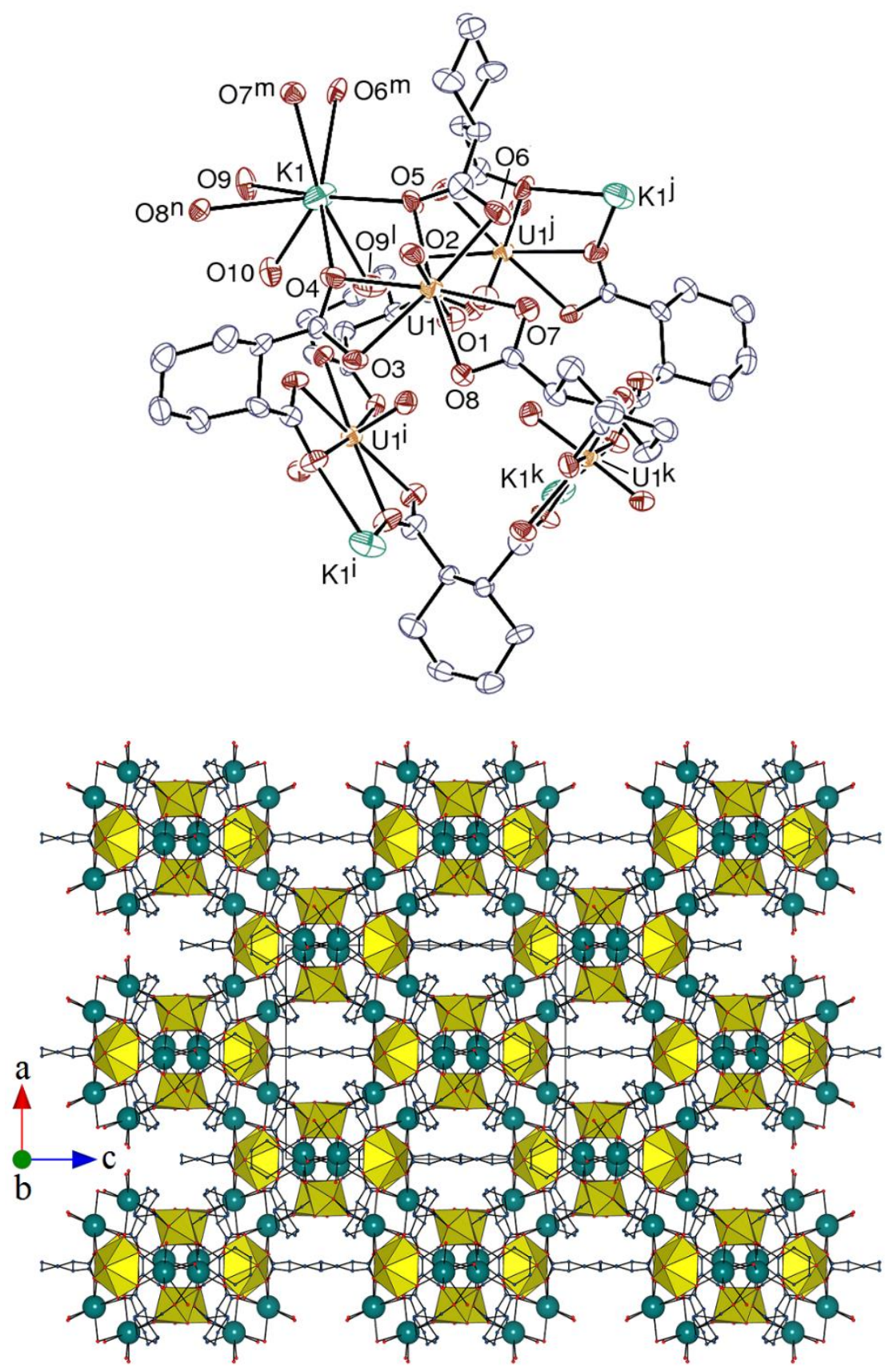
Figure 3
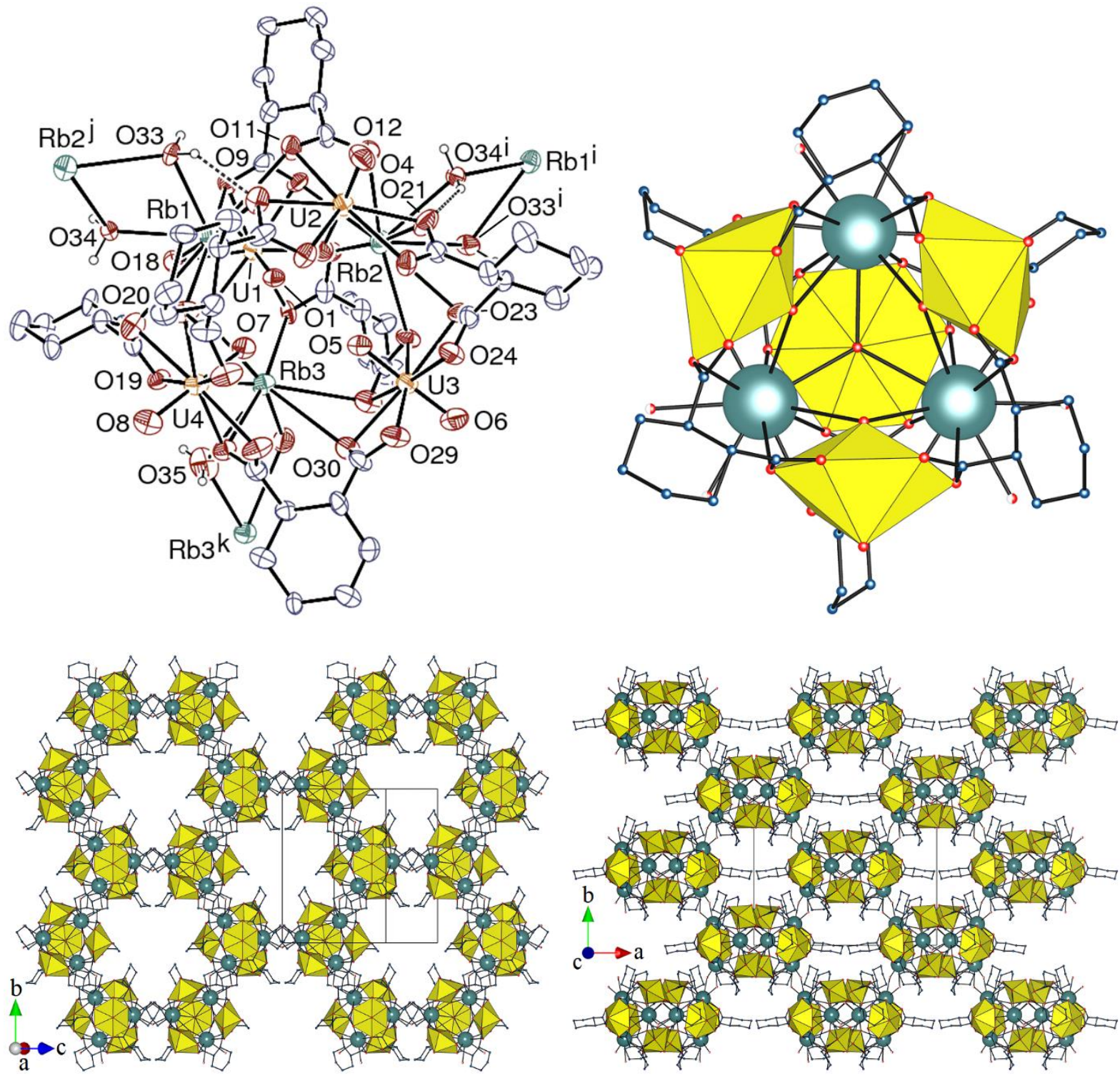
Figure 4
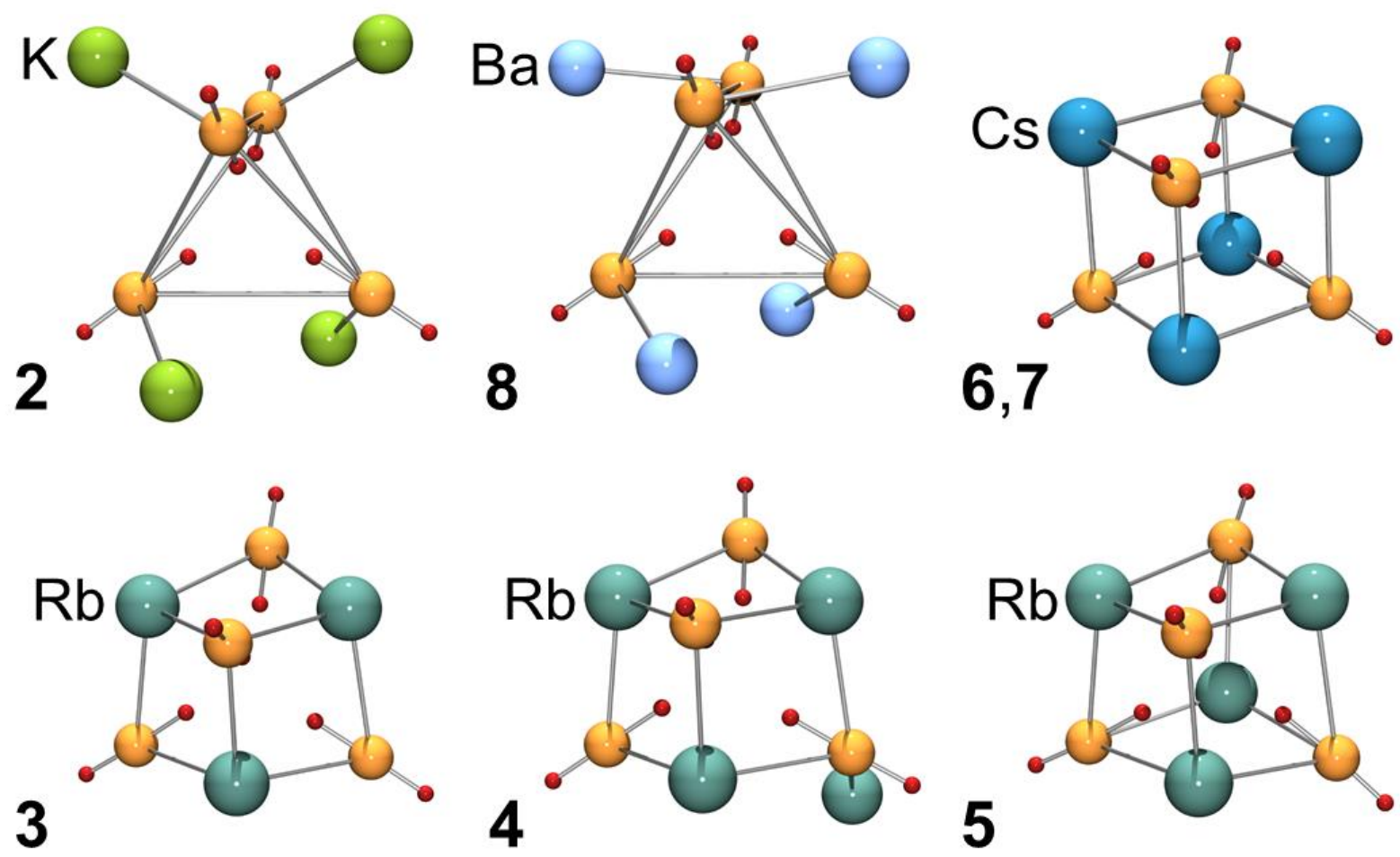
Figure 5
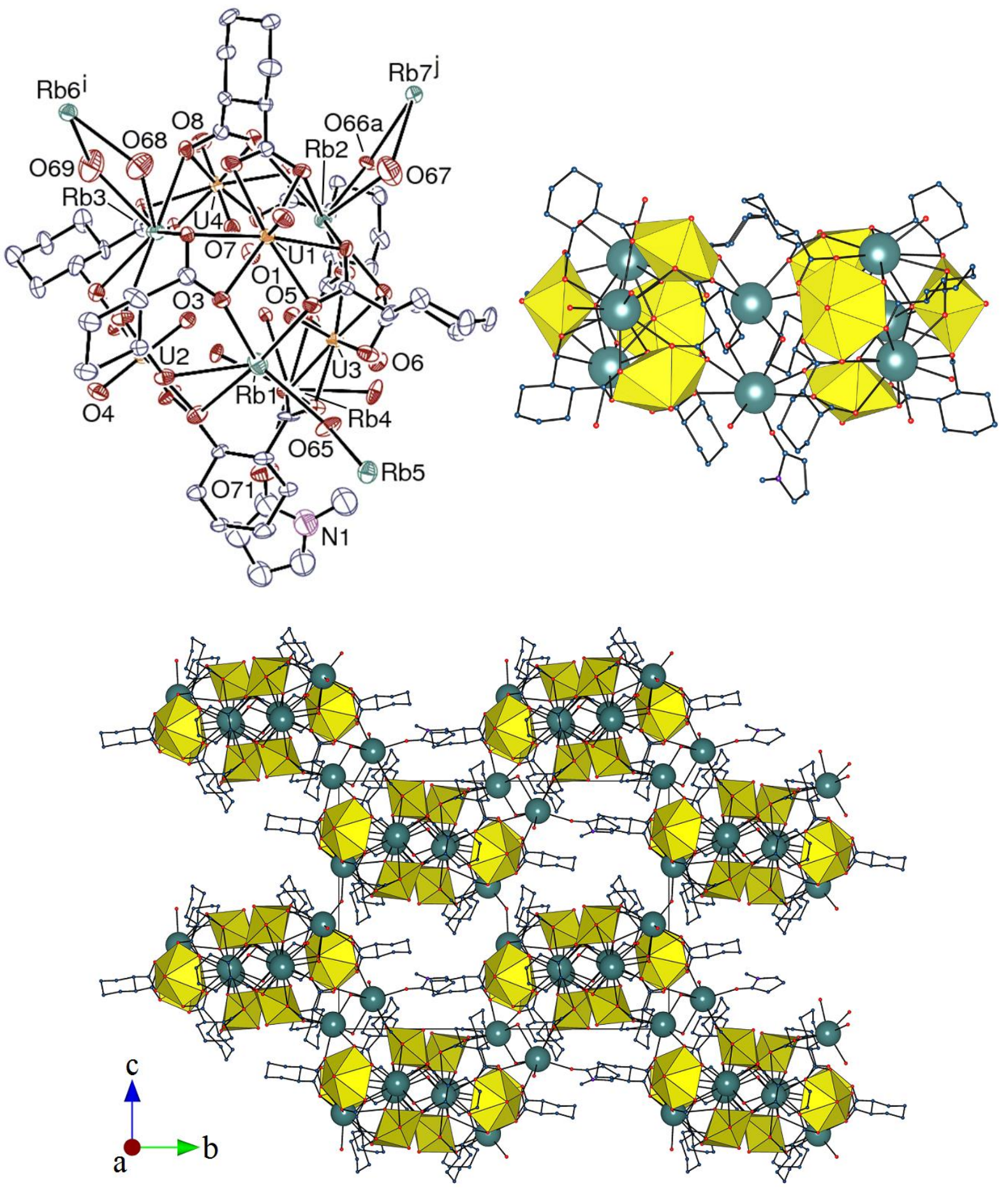
Figure 6
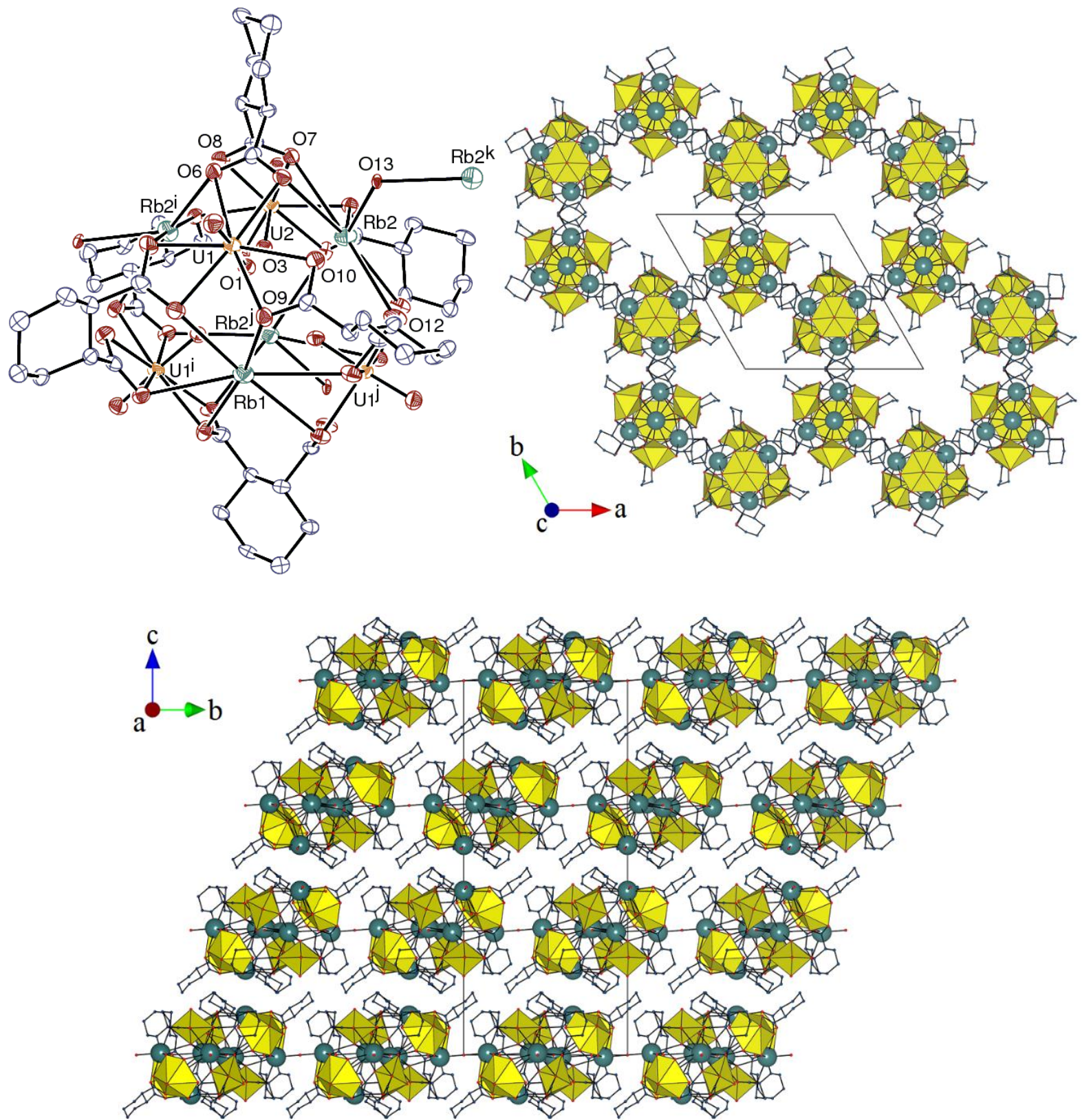
Figure 7
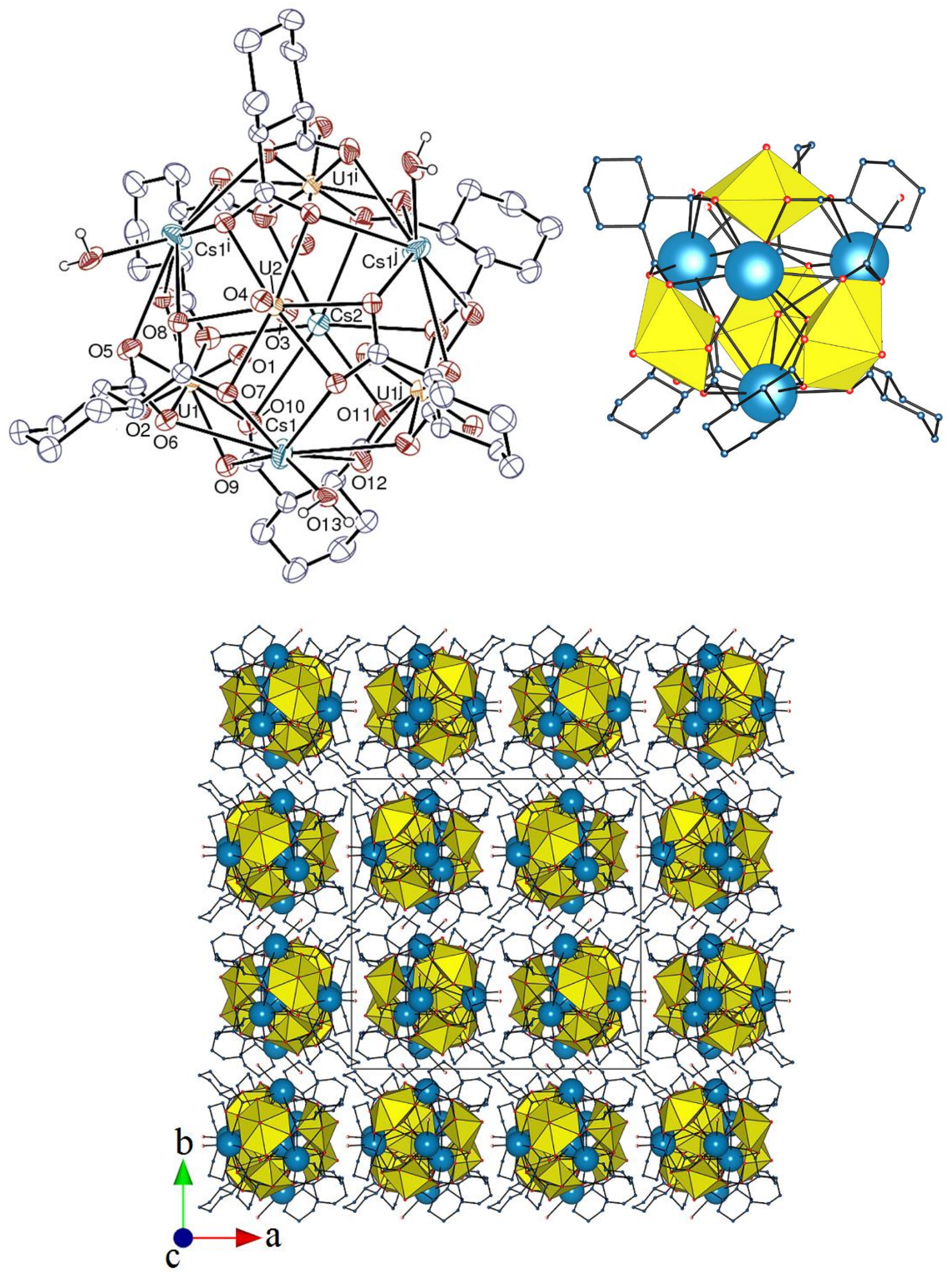
Figure 8
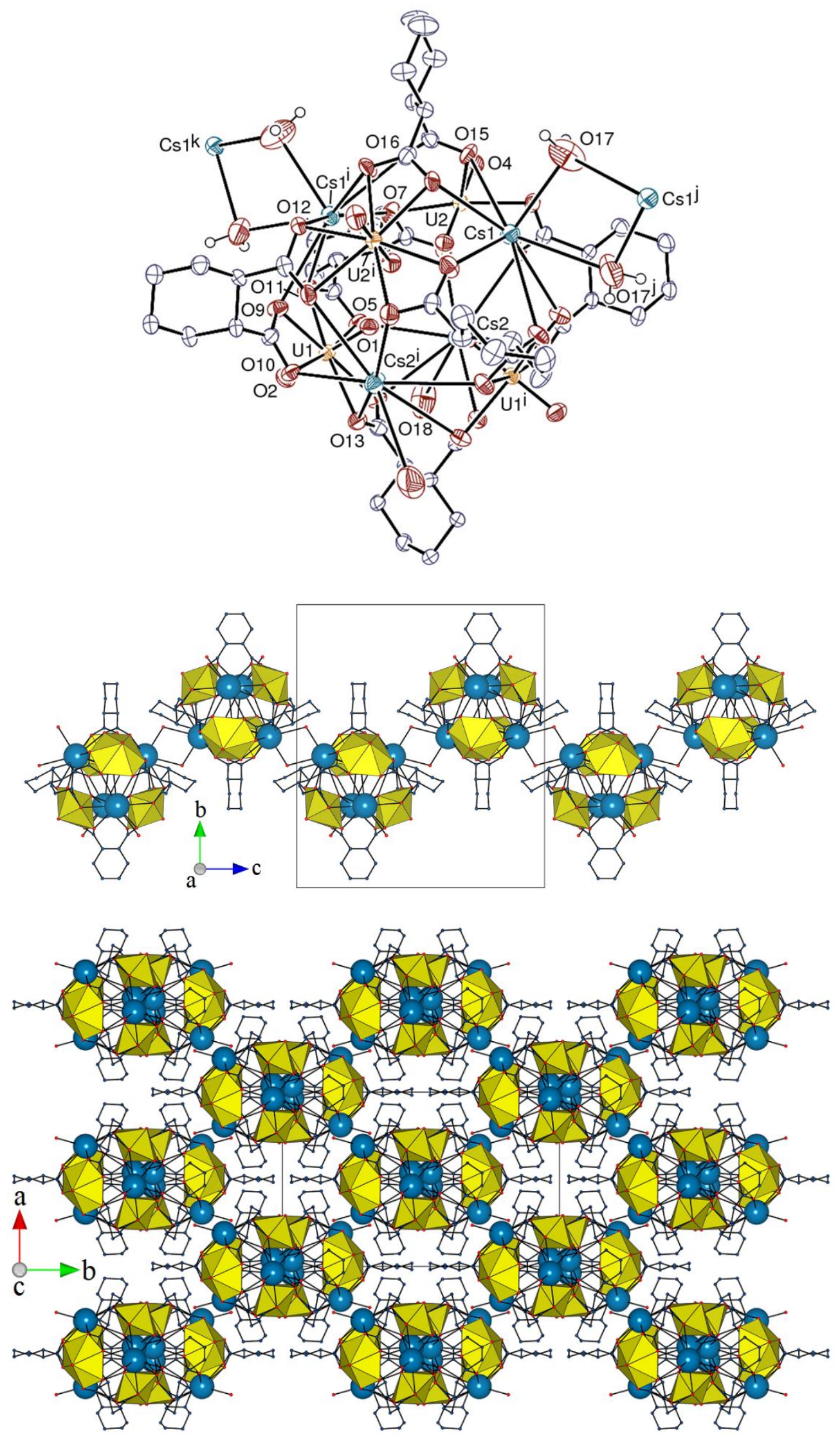
Figure 9
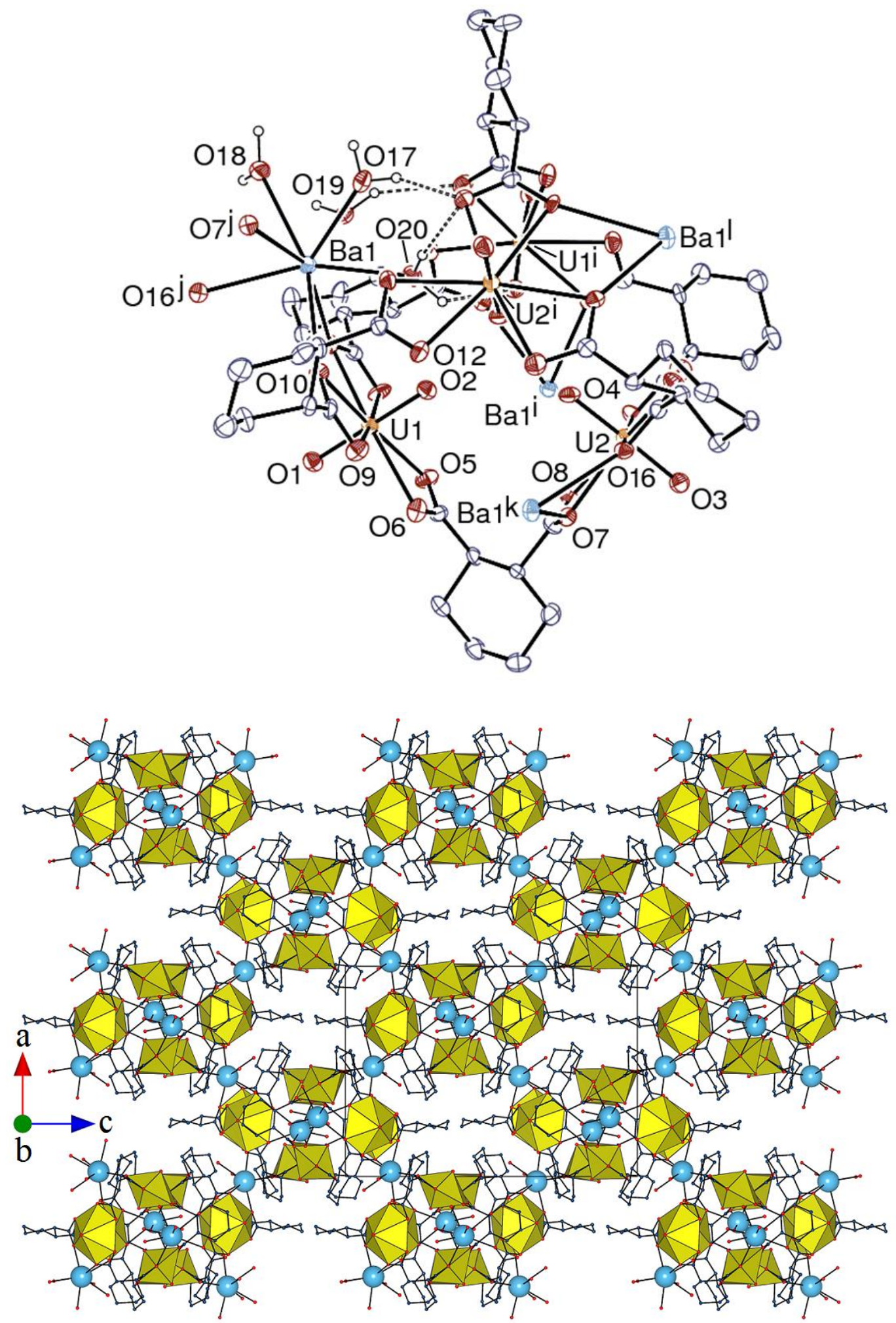
Figure 10

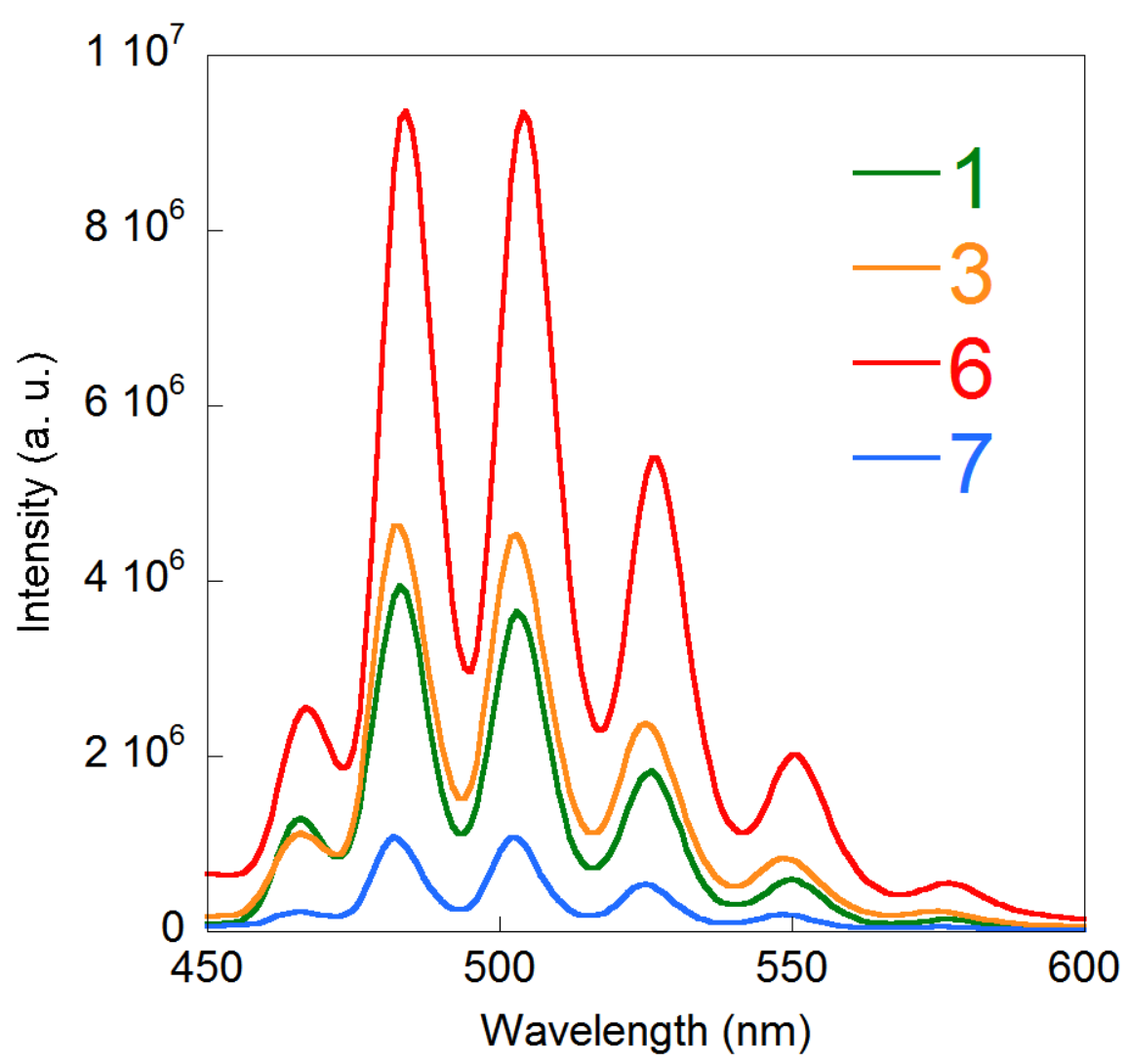




\title{
For Table of Contents Use Only
}

\section{Tetrahedral and Cuboidal Clusters in Complexes of Uranyl and Alkali or Alkaline-Earth Metal Ions with rac- and (1R,2R)-trans-1,2-Cyclohexanedicarboxylate}

\author{
Pierre Thuéry and Jack Harrowfield
}

Uranyl ions readily form anionic tetranuclear, pseudotetrahedral clusters with $r a c$ - and $(1 R, 2 R)$ trans-1,2-cyclohexanedicarboxylates. Different modes of association occur in the presence of alkali or alkaline-earth metal cations, those with smaller ionic radii $\left(\mathrm{Na}^{\mathrm{I}}, \mathrm{K}^{\mathrm{I}}, \mathrm{Ba}^{\mathrm{II}}\right)$ linking uranyl clusters into higher dimensionality assemblies, and those with larger radii $\left(\mathrm{Rb}^{\mathrm{I}}, \mathrm{Cs}^{\mathrm{I}}\right)$ being included in heterometallic cuboidal clusters.

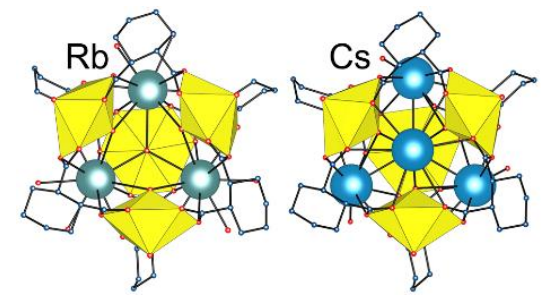

